\title{
Remote Sensing of the Earth with Spaceborne Imaging Radars
}

\author{
Charles Elachi, ${ }^{*}$ JoBea Cimino, $†$ and James Granger $\ddagger$ \\ Jet Propulsion Laboratory, California Institute of Technology, \\ Pasadena, California
}

\section{Abstract}

Spaceborne imaging sensors in the visible, infrared and passive microwave have been used to observe and study the Earth's surface since the early stages of the space program. More recently, active microwave imaging sensors (radars) have been developed to extend our capability to study the Earth surface processes. Imaging radars, flown on Seasat (1978) and the Shuttle (1981, 1984), acquired synoptic images of a variety of geologic, biologic, and oceanographic features and provided new insight in some of the land and ocean processes. Subsurface synoptic imaging was achieved for the first time in some of the arid regions of the world. Soil moisture distribution after a rainstorm was clearly delineated, opening the possibility of its monitoring on a global basis. Polar ice distribution and dynamics over large areas in the Beaufort Sea were monitored over a three-month period, thus allowing the possibility of operational observation of ice dynamics in support of polar navigation. The successful development and flight of these spaceborne imaging radars was the result of major technological developments in the 1970s. They used some of the largest spaceborne lightweight planar array antennas $(2 \times$ $10 \mathrm{~m})$ with printed radiating elements. The transmitters were fully solid state and generated a $1 \mathrm{~kW}$ peak power signal at $L$-band $(1.2 \mathrm{Ghz})$. The processing of the received data to generate the high-resolution $(25$ to $40 \mathrm{~m})$ imagery was done using both optical and digital processors. More advanced imaging radar systems are under development.

Copyright (c) 1985 by the American Institute of Aeronautics and

Astronautics, Inc. All rights reserved.

*Principal Investigator, SIR-A and SIR-B Experiments; currently,

Senior Research Scientist.

† Senior Scientist, Science Collaborator, SIR-B Experiment.

$¥$ Cognizant Engineer, SIR-A Experiment. 
Multispectral, multipolarization imaging radar systems are under development for flight in the late 1980s, thus extending our capability of detailed studies of the Earth surface processes and the nature of its cover. Extremely fast SAR digital processors are under development using the most advanced integrated circuits and allowing real-time processing of the data. This corresponds to a computational capability of $6 \times 10^{9}$ operations/s. This chapter consists of a review of the recent scientific and technological developments in the field of Earth observation with spaceborne imaging radars and an overview of planned activities in the 1980s.

\section{Introduction}

Over the last 6 years, two space missions allowed the acquisition of the first high-resolution radar images of the Earth's surface. In 1978, the Seasat satellite acquired extensive radar coverage over North America, western Europe, the North Atlantic, and the Northeast Pacific.l In 1981, the Shuttle Imaging Radar (SIR-A) acquired a limited amount of data over a wide range of regions around the world. 2 Both missions were of an experimental nature and operated for a limited time period. However, the imaging radar data acquired during these missions have given us the first insight into the use of these data in a wide range of largescale geoscientific research and application topics, including structural and lithologic mapping, arid surfaces imaging through thin alluvium and sand cover, soil moisture mapping, forest clear-cutting, ocean wave pattern studies and ship routing. Both sensor systems used the synthetic aperture radar (SAR) technique to acquire the high-resolution images. Spaceborne photography became available in the early 1960 s with the advent of the space age. This was followed in the late 1960s and 1970s with the acquisition of multispectral visible and infrared (i.r.) imagery, thermal imagery, and passive microwave imagery. These sensors allowed us to acquire information about the surface by studying its emitted energy in the microwave and $i . r$. regions of the spectrum and the reflected energy in the visible and neari.r. regions. All of these sensors are passive in nature, i.e., they detect the energy generated by the surface or the sun energy reflected by the surface.

The SAR imaging sensor provides information about the surface by measuring and mapping the reflected energy in the microwave region, thus extending the capability of 
sensing the surface properties into a new dimension. In addition, because it uses its own energy and operates at a relatively long wavelength, it acquires surface imagery at all times, i.e., day or night and through cloud cover. Thus, it has the unique capability required for continuous monitoring of dynamic surface phenomena.

The imaging resolution of passive sensors is equal to their angular resolution (i.e., observing wavelength over aperture size) multiplied by the range between the sensor and the area or object being imaged. Thus, the size of the resolution element increases linearly with the observing wavelength and sensor altitude and is inversely proportional to the aperture size. In the optical and $i . r$. regions, very high resolution is acheivable from orbit with reasonably sized apertures because of the short operating wavelength. In the microwave region, the operating wavelength is relatively large and apertures of many hundreds of meters to many kilometers are required to achieve high resolution of tens of meters or less. This, of course, is impractical at the present time.

The SAR sensor circumvents this limitation by using the ranging and Doppler tracking capability of coherent radars to acquire high-resolution images of the surface from orbital altitudes. Two neighboring targets are separated by their differential time delay and Doppler history, neither of which is a function of the distance to the sensor. Thus, the resolution for a SAR system is independent of the sensor altitude. This unique advantage does impose some restriction on the sensor imaging swath, antenna size, and power requirements. Because the SAR uses the Doppler history to achieve high resolution in one of the spatial dimensions, each pixel is generated by processing a large number of successive echoes. This leads to a large number of arithmetic operations in order to generate the image. The development of digital processors for spaceborne SAR data is a very active and challenging research field. The basic properties of spaceborne SAR systems are discussed in Sec. II and the technological aspects of the sensor and processor are presented in Sec. VI.

The Seasat imaging radar acquired surface images during the summer of 1978 with a resolution of $25 \mathrm{~m}$, illumination angle of $23 \mathrm{deg}$ from vertical, L-band frequency $(23 \mathrm{~cm}$ in wavelength) and $H-H$ polarization. The highlights of the corresponding scientific results can be found in a number of scientific articles (e.g., Refs. 3-6). The analysis of the Seasat data clearly indicates that spaceborne radar data are an important tool in a number of applications, including structural mapping, lithologic mapping when used 
in conjunction with visible and near-i.r., soil moisture delineation, vegetation type identification when used in conjunction with Landsat data, ocean wave pattern studies and forecasting, internal wave studies, ocean bathymetry in very shallow regions, and polar ice structure and dynamics. Unfortunately, the Seasat data were acquired over only one season.: This did not allow the study of dynamic phenomena over a year's time scale.

In 1981, the SIR-A acquired a limited amount of data over a number of regions around the world. The SIR-A characteristics were similar to the Seasat SAR except the resolution was $40 \mathrm{~m}$ and the illumination angle was 50 deg. The highlights of the SIR-A results are summarized in Refs. 7-9. The SIR-A results confirmed some of the Seasat results, with the following additions:

1) In arid and hyperarid regions, the radar waves will penetrate through a surface layer of sand or alluvium several meters deep. This opens a whole new field of nearsubsurface imaging of buried geologic, hydrologic, and possible archeologic features.

2) In tropical forest regions, a spaceborne radar can be used to delineate and monitor deforestation.

3) Spaceborne stereo radar images can be used for topographic contours mapping.

In addition, a comparison of the imagery acquired by SIR-A and Seasat showed that multiple indidence angle radar images are required to be able to fully map both small-scale (roughness) and large-scale (topography) features.

Examples of these different applications are given in Secs. III and IV. Section $V$ contains a detailed description of the Seasat and SIR-A sensors as well as of the SIR-B sensor that was flown in the fall of 1984. Future sensor systems planned for flights in the late 1980 s and early 1990 s are briefly dicussed in Sec. VII.

\section{Principle of Spaceborne Synthetic Aperture Imaging Radars}

In the synthetic aperture technique, the Doppler information in the returned echo is used simultaneously with the time delay information to generate a high-resolution image of the surface being illuminated by the radar. The radar usually "looks" to one side of the moving platform (to eliminate right-left ambiguities) and perpendicular to its line of motion. It transmits a short pulse of coherent electromagnetic energy toward the surface. Points equidistant from the radar are located on successive concentric spheres. The intersection of these spheres with the surface 
gives a series of concentric circles centered at the nadir point (Fig. 1). The backscatter echoes from objects along a certain circle will have a well-defined time delay.

Points distributed on coaxial cones, with the flight line as the axis and the radar as the apex, provide identical Doppler shifts of the returned echo. The intersection of these cones with the surface gives a family of hyperbolas (Fig. 1). Objects on a specific hyperbola will provide equi-Doppler returns. Thus, if the time delay and Doppler information in the returned echoes are processed simultaneously, the surface can be divided into a coordinate system of concentric circles and coaxial hyperbolas (shown in fig. 1) and each point on the surface can be uniquely identified by a specific time delay and specific Doppler. The brightness assigned to a specific pixel (picture resolution element) in the radar image is proportional to the echo energy contained in the time delay and Doppler bins that correspond to the equivalent point of the surface being imaged. The resolution capability of the imaing system is thus dependent on the measurement accuracy of the differential time delay and differential Doppler (or phase) between two neighboring points on the surface.

In actuality, the situation is somewhat more complicated. The radar transmits a pulsed signal that is neces-

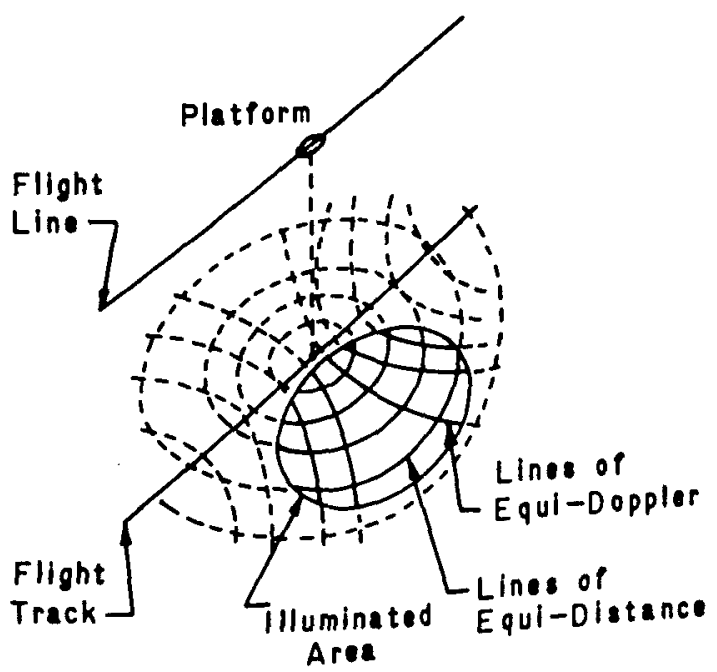

Fig. 1 Synthetic aperture radar geometry. The constant time-delay and constant Doppler lines form the radar imaging coordinate system. The backscatter return from each cell on the surface can be uniquely determined by filtering from the total return the energy in the appropriate time-delay bin and Doppler shift bin. 
sary to obtain the time-delay information. To obtain the Doppler information unambiguously, the echoes from many pulses are required to meet the Nyquist sampling criterion. Thus, as the moving platform passes over a certain region, the recorded series of echoes contains a complete Doppler history and range-change history for each point on the surface being illuminated. These complete histories are then processed to identify uniquely each point on the surface and to generate the image. $10-14$. This is why a very large number of operations are required to generate one pixel in the image -- such is not the case in optical sensors. A simplified comparison is that the radar sensor generates the equivalent of a hologram of the surface and further processing is required to obtain the actual image. This processing can be done either optically or digitally.

In the case of spaceborne sensors, there are additional effects ${ }^{2}, 14$ that are not encountered with airborne sensors:

1) The rotation of the Earth relative to the spacecraft adds a Doppler shift that must be accounted for during processing. This Doppler shift varies as a function of latitude and inclination of the orbit.

2) The orbit eccentricity causes an altitude rate of change that translates into a Doppler shift which must be eliminated.

3) The ionospheric granularities introduce phase scintillations that induce errors in the Doppler measurements.

4) The far distance to the surface requires that many pulses be transmitted before the echo from the first one is received. Attention must be given to the timing of the transmitted and received echoes.

The synthetic aperture imaging technique has one unique characteristic. The resolution capability is dependent on the measurement accuracy, in the range dimension, of the differential time delay between two different points and, in the azimuth dimension, of the Doppler shift from a target. Neither of these measurements is related to the absolute distance from the radar to the surface. Thus, the resolution of an imaging SAR is independent of the altitude of the platform. Spaceborne and airborne SARs with similar characteristics will have the same resolution capability. The main difference is that spaceborne sensors require more transmitted power to be able to obtain the necessary echo signal-to-noise ratio. The size of the antenna aperture is determined mainly by the width of the swath being imaged and the observing geometry, not by the resolution. 
Surface Interaction Mechanisms

The brightness of an individual pixel in a radar image is a direct representation of the backscatter cross section of the corresponding area on the surface being imaged. The backscatter cross section is dependent mainly on the physical (e.g., slope, roughness and near-surface inhomogeneities) and electrical (e.g., dielectric constant) properties of the surface, as well as the radar wave characteristics (incidence angle, frequency, and polarization state). A number of interaction mechanisms contribute to the backscattered energy. 5 Bragg scattering is dominant at relatively large incidence angles and for relatively well-organized surfaces. Rayleigh scattering is dominant in the case of discrete objects. Specular reflection is of particular importance at near-vertical incidence and multiple scattering plays a key role in depolarization of the incident wave.

In its simplest form, the behavior of the backscatter cross section as a function of incidence angle is shown in sketch form in Fig. 2. Because of the numerous surface parameters influencing the backscatter cross section, a complete description of the surface properties will most likely require multiple observations with different radar parameters. If the radar system operates at a single

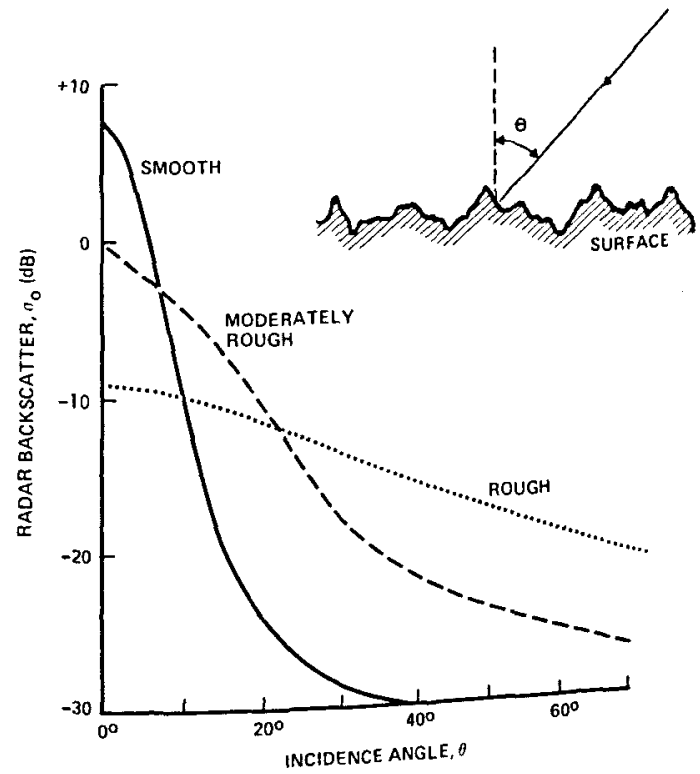

Fig. 2 Illustrative example of backscatter as a function of incidence angle. 
frequency, it can be seen from Fig. 2 that large incidence angles are more favorable for observing surface topography because of the resulting shadowing. Small incidence angles are also desirable because of the high sensitivity of backscatter to variations in the surface slope. Intermediate incidence angles are more favorable for observing surface roughness. Multiple incidence-angle observation will allow the acquisition of information about different surface properties and will allow the use of stereo techniques.

Multiple-frequency observation is of particular interest at intermediate angles in order to acquire a measure of the spectra characteristics of the surface roughness. Multiple-polarization observations provide information about volumetric and multiple scattering and will tend to suppress the effects of the large-scale topography (i.e., slope changes).

Noise in SAR Systems: Thermal and Speckle Noise

Neglecting quantization noise, the two types of noise to be considered in a radar design are the thermal and speckle. The former is an additive noise due to the noise temperature at the input of the receiver. The signal-tothermal noise ratio can be improved by increasing the transmitted peak power or decreasing the receiver temperature. This is the type of noise encountered in real-aperture radar systems.

Speckle noise is due to the coherent nature of the SAR image-formation process. This noise gives the radar image a fine texture similar to what is observed when a scene is illuminated with laser light. The speckle noise is proportional to the reflected signal power. Thus, it is a multiplicative noise that cannot be reduced by increasing the transmitted power. The speckle noise can be reduced only by averaging independent looks.

Before detection, the speckle noise is assumed to be a zero-mean Gaussian noise on each of the in-phase and quadrature components. After detection, the intensity in an image pixel then has an exponential probability distribution of the form

$$
p(I)=\left(1 / I_{0}\right) e^{-I / I_{0}}
$$

where $I_{0}$ is the average return in the absence of speckle. As multilooks are coherently added, the speckle variance is reduced and becomes chi-squared $\left(x^{2}\right)$ and di stributed with $2 N$ degrees of freedom, where $N$ is the number of independent 
looks. This gives a probability density function for the intensity of an image pixel as

$$
p(I)=\frac{1}{\Gamma(N)} \frac{1}{I_{0}}\left(\frac{I}{I_{0}}\right)^{N-1} e^{-I / I_{0}}
$$

This distribution has a mean of $\mu=\mathrm{NI}_{0}$ and a standard deviation $\Sigma=\sqrt{\mathrm{N}} \mathrm{I}_{0}$.

One measure of an image radiometric resolution, for a stationary scene, is

$$
Q=10 \log \frac{\mu+\Sigma}{\mu-\Sigma}=10 \log \frac{\sqrt{N}+1}{\sqrt{N}-1}
$$

which clearly shows that higher values of $N$ are desirable. However, for $N>25$ (e.g., $Q=1.8 \mathrm{~dB})$, large increases in $N$ give only sman improvements in $Q$. This should be traded off with the fact that increasing $N$ immediately degrades the image resolution in a proportional way.

A detailed theoretical study with experimental verification of the speckle noise property has been made by Bennett and McConnel1.15

\section{Applications in Land Observations}

\section{Surface Geology}

The response of radar backscatter to changes in the surface topography on both large and small scales make it a powerful tool for geologic structural mapping. Surface details are best observed when the illumination direction is perpendicular to the topographic trend of the surface feature. Unlike visible and infrared systems, which have illumination geometries tied to the sun, the self-illuminating radar has some control over the illumination geometry. Changes in the slope of a few degrees can change the radar backscatter significantly and therefore subtle topographic features can often be detected. On a a smaller scale, changes in the roughness of the surface on the scale of several centimeters can be related to lithology. Rock types that have undergone different erosional processes can be discriminated using the radar. The presence of vegetation associated with different types of soils can be used to delineate underlying geologic structures.

The potential for doing structural geologic mapping using spaceborne imaging radars was clearly demonstrated with the Seasat SAR, even though the imaging geometry was 
selected for oceanographic studies. Figure 3 depicts the folded Appalachian Mountains in Pennsylvania. Large plunging synclines and anticlines are easily mapped in the radar image. The heavily forested mountain slopes exhibit a smooth image texture due to the uniformity of the forest canopy. The more diverse image tone of the valleys is due to the variety of surface cover, including urban, rural, and agricultural regions. Regional drainage patterns are easily traceable across the older structure of the Appalachians. The most apparent river is the Susquehanna River. A more detailed study of Seasat imagery acquired over the Appalachians by Ford ${ }^{16}$ showed that the orientations of short geologically uncorrelated lineaments are easily

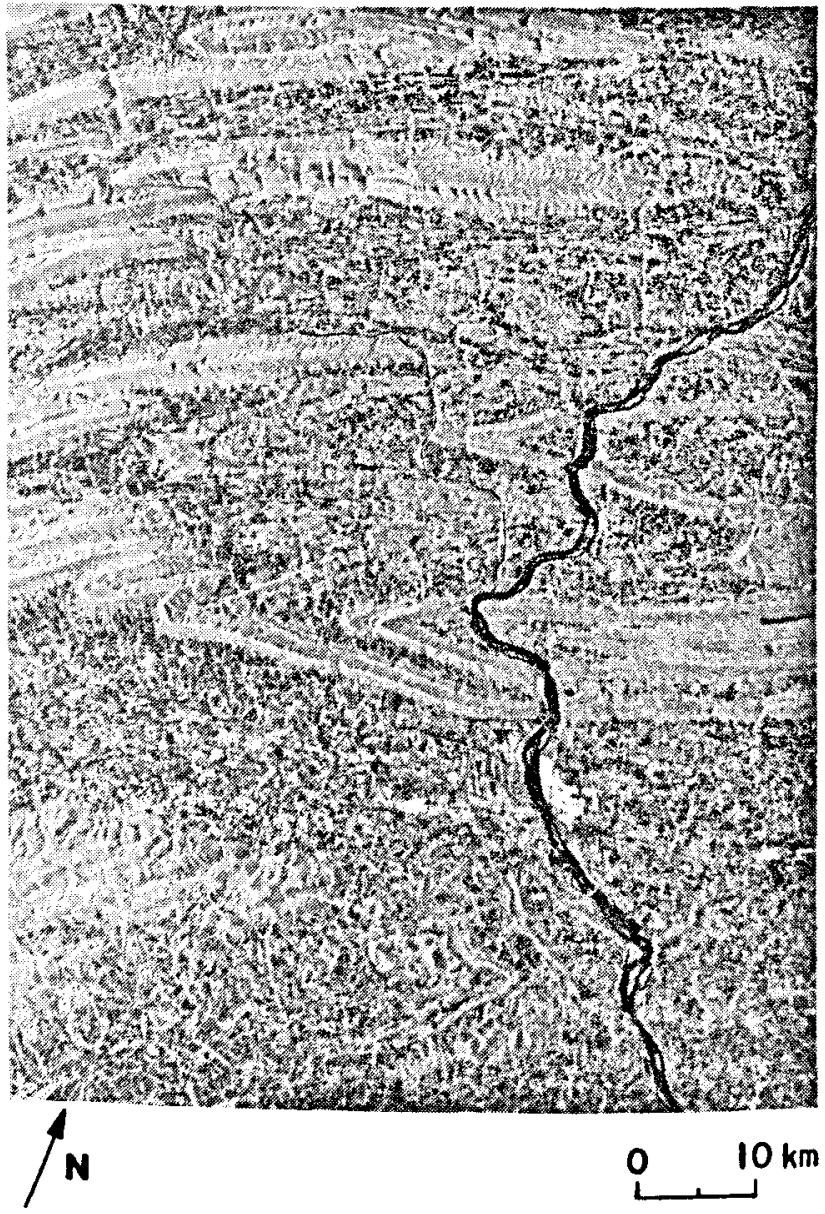

Fig. 3 Seasat SAR image of the Appalachian Mountains in Pennsylvania. 
interpreted. The observed coincidence of some of the uncorrelated lineaments with magnetic and gravitational trends in the basement and alignment with known structural features was the basis of further geologic study in this area.

One of the more well-known geologic features is the San Andreas Fault. This famous fault was imaged by the Seasat SAR and is shown in Fig. 4. To the northeast are the Antelope Valley and the Mojave Desert. These regions are relatively smooth and level, therefore they appear dark on the radar image. To the southwest are the San Gabriel Mountains and the Angeles Forest. Because of the steeper, more rugged terrain, the image tone is much brighter here than northeast of the fault. In the northern portion of the image, the San Andreas Fault is intersected by the

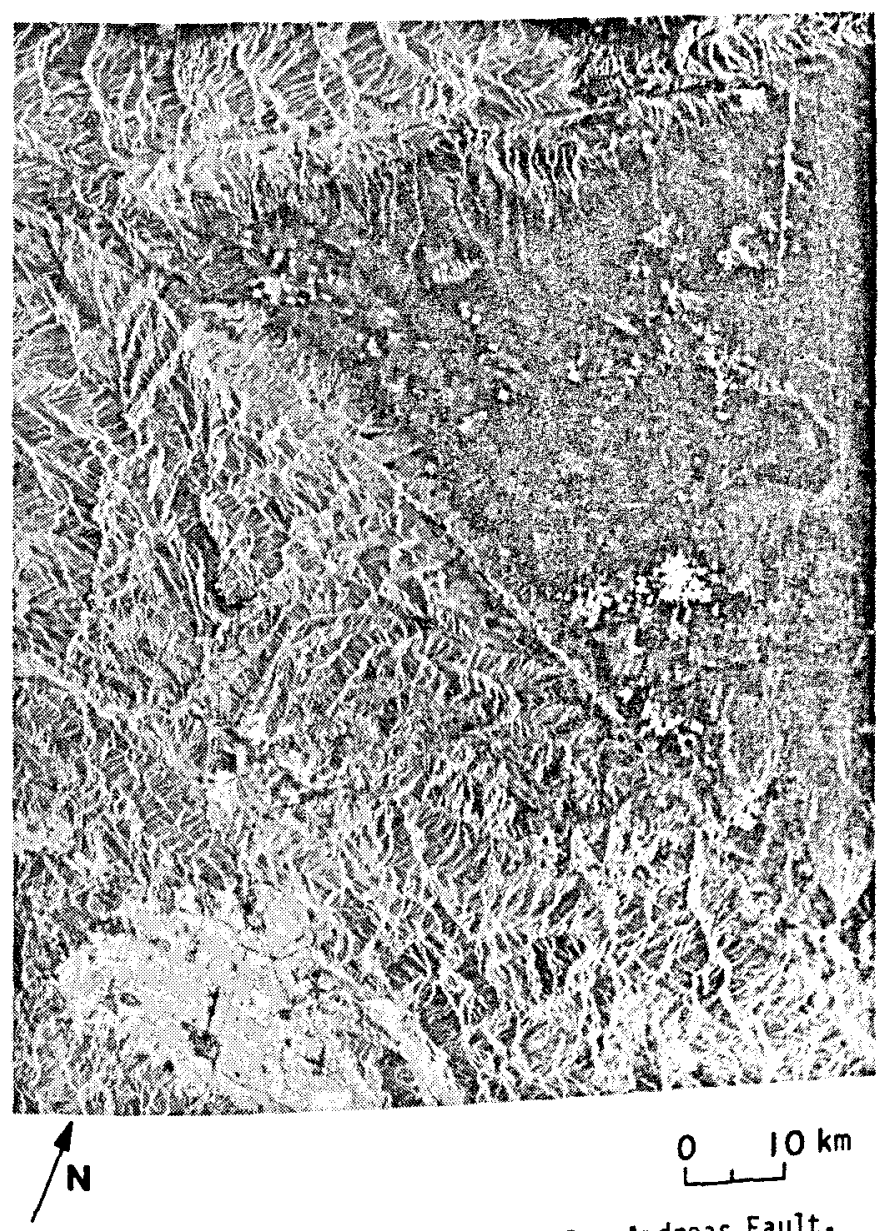

Fig. 4 Seasat SAR image of the San Andreas Fault. 
Garlock Fault. The San Andreas Fault is traceable both because of tis pronounced linear scarp and because of the diversity in terrain roughness on either side of the fault. The trace of the Garlock Fault, however, is obscured due to radar layover, a geometric problem resulting from imaging steep mountains with a steep incidence angle, and is traceable only because of the diversity in terrain roughness on either side of the fault.

A more detailed study of the San Andreas Fault was done by Sabins et al.17 A portion of the fault in the Durmid Hills of southern California imaged by Seasat was used in the study. Again, the fault was expressed as a prominant southeast trending tonal lineament that is bright on the southwest side and dark on the northeast side. The bright radar return on the southwest side was due to the rough weathered surface of the Borrego formation. The dark signature to the northeast was due to the smooth sand and silt deposits of Lake Cahuilla.

Spaceborne imaging radar data has also been used extensively to study sand dunes. A detailed assessment of the ability of orbital SAR systems to provide useful information about sand dunes was done by Blom and Elachi. 18 In summary, the backscatter mechanism of sand dunes is primarily specular. Observed surface irregularities of sand dunes are inadequate to cause Bragg or incoherent scattering at imaging radar wavelengths. This constrains allowable incidence angles for imaging sand dunes to less than the angle of repose for dry sand (about $33 \mathrm{deg}$ ). Radar images made without meeting this criterion will show sand dunes as dark areas and interpretation, and perhaps even recognition of the existence of sand dunes, is not possible.

Since dune fields generally contain very directional elements, the availability of two illumination directions is highly desirable. Linear features more than about 60 deg from perpendicular to the illumination direction will not be visible unless they have considerable topographic variability. In each of the study areas where Seasat data from both illumination directions were available, a significant contribution was made to the understanding of the dune structures by the additional illumination direction image. This information is, in fact, required for inference of wind regimes responsible for the dune structures. Determination of dune structures such as the Mohawk, Cadiz, and Sonora dunes using Seasat SAR data would not have been possible without two illumination directions. lineare types imaged by Seasat included star, dome, linear, and crescentic. All of these dune types can be 
recognized on the orbital images providing they are favorably oriented to the radar illumination. Identification of star dunes is greatly facilitated by the addition of another illumination direction. Other common types of aeolian features, sand sheets and stringers, do not seem to have a bright radar return unless they are vegetated, as in the Algodones Dunes (Fig. 5). Without the backscatter contribution from the vegetation, they may be imaged as dark areas unless they have considerable topography.

SIR-A also acquired a variety of imagery over many types of terrain including dissected plateaus, volcanic fields, salt pans, drainage features, and sand dunes. Figures 6 and 7 are two examples of the diversity of terrain imaged by SIR-A. The structure shown in Fig. 6 is a linear

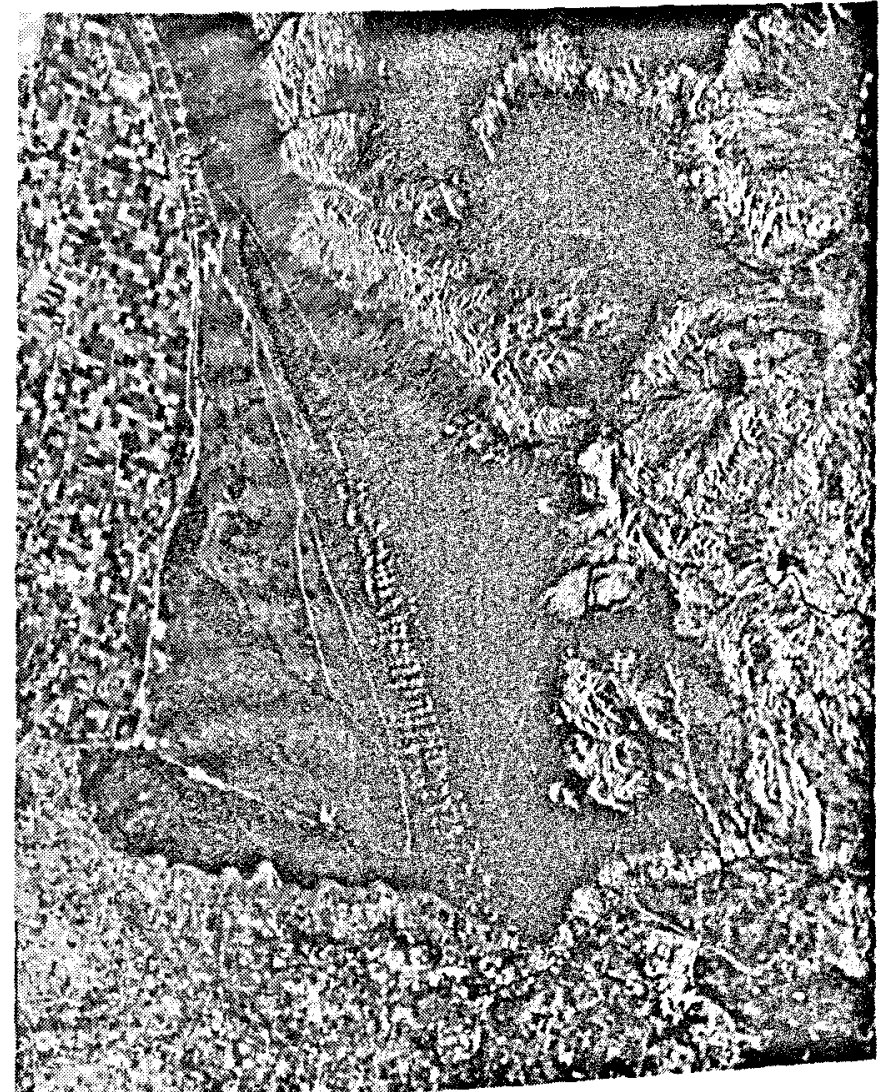

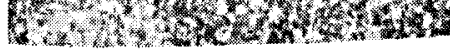

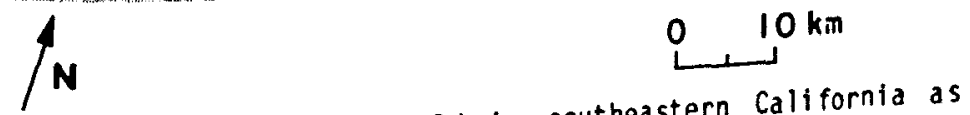

Fig. 5 The Algodones Dune Field in southeastern California as imaged by Seasat. 
extension of the Altyn Tagh Fault.19 In the eastern portion of the image, the fault bends southwestward to join the Gansu Fault. Both faults are major left-lateral strike slip faults and are part of a fault system that extends over $3000 \mathrm{~km}$ from the Tarim Basin to the Shanxi Graben. Along the fault (which extends from the lower left corner of the image to the right center), evidence of truncation of ridges and left-lateral drag is apparent. The large alluvial fans in the upper portion of the image and in the lower right corner represent a different type of terrain. Differences in the grain size of the deposits are responsible for variations in image tone brightness along the fan. Evidence of man is also apparent in the image. Railroad tracks and roadways extending across the center of the image and across the large fan are easily discernable. Another type of terrain is shown in Fig. 7. This image, also acquired by SIR-A, is of the Lake Chad Basin in the intertropical convergence zone. The dunes in the image are oriented with their long axes transverse to the prevailing southwest and northeast Saharan winds. When Lake Chad receded, it left behind widespread arrays of large sand dunes standing above the interdune flats. The identification of the dunes on the radar image is possible because of the bright response of the vegetated interdune flats, which are grassy savannas. The overall irregularity of the dunes is typical of old, vegetated, inactive dunes that have undergone weathering and erosion.

The unique capability of radar to image through clouds makes it an extremely useful tool for mapping in tropical

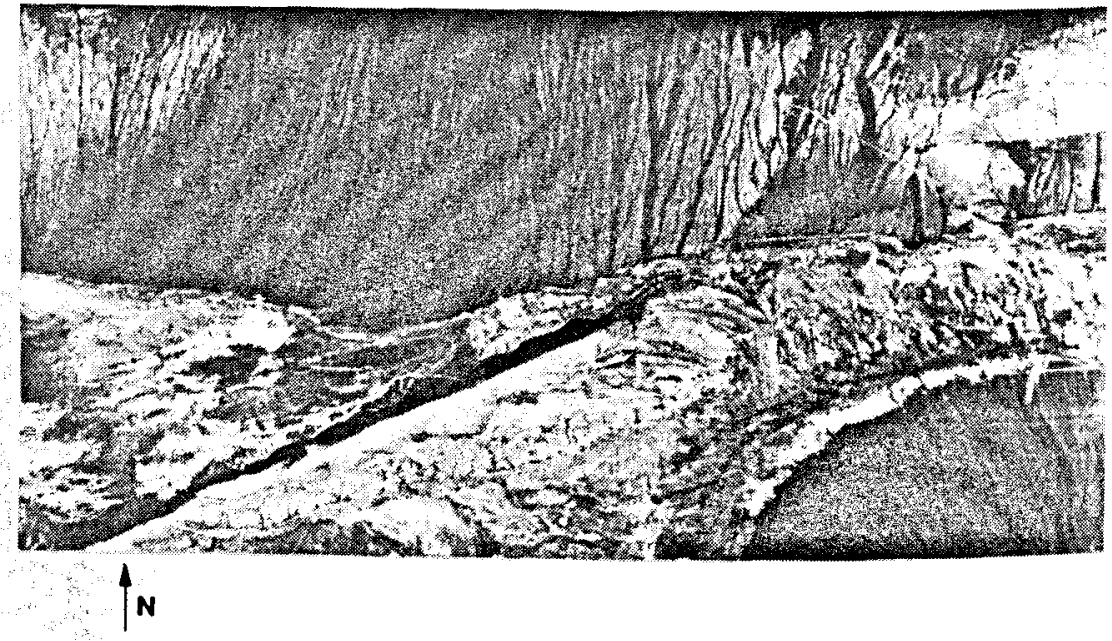

Fig. 6. Altyn Tagh Fault in Gansu China as imaged by SIR-A. 
regions such as Indonesia. In addition, Indonesia is a very heavily vegetated region. Therefore, although radar waves can only partially penetrate the dense vegetation, the variation in radar backscatter due to large- and smallscale surface roughness provide a means of mapping a variety of terrain types. An extensive study of the lithologic and structural information available in SIR-A images of portions of Kalimantan and Irian Jaya was done by Sabins. 20 The results of this study showed that it was possible to map six major terrain categories including carbonate rocks, clastic rocks, volcanic rocks, alluvial deposits, melange complexes, and metamorphic rocks. Figure 8 shows four of these terrain types in the southeastern Vogelkop region. A variety of structural geologic features were also easily mapped using the radar imagery, including foldbelts, uplifts, basins, and faults. Also visible in Fig. 8 is the Lengguru foldbelt, a doubly plunging syncline with an arcuate axial trace.

Subsurface Imaging

One of the unique properties of radar waves is that they usually sense both the surface and the near subsurface. The depth of penetration is strongly dependent on the absorption and scattering properties of the subsurface layer. It usually ranges from a fraction of a wavelength up to about 10 wavelengths or more, depending primarily on the moisture content of the subsurface layer. Thus, in the case of an L-band (25 cm wavelength) imaging radar, the subsurface penetration can reach many meters. This large

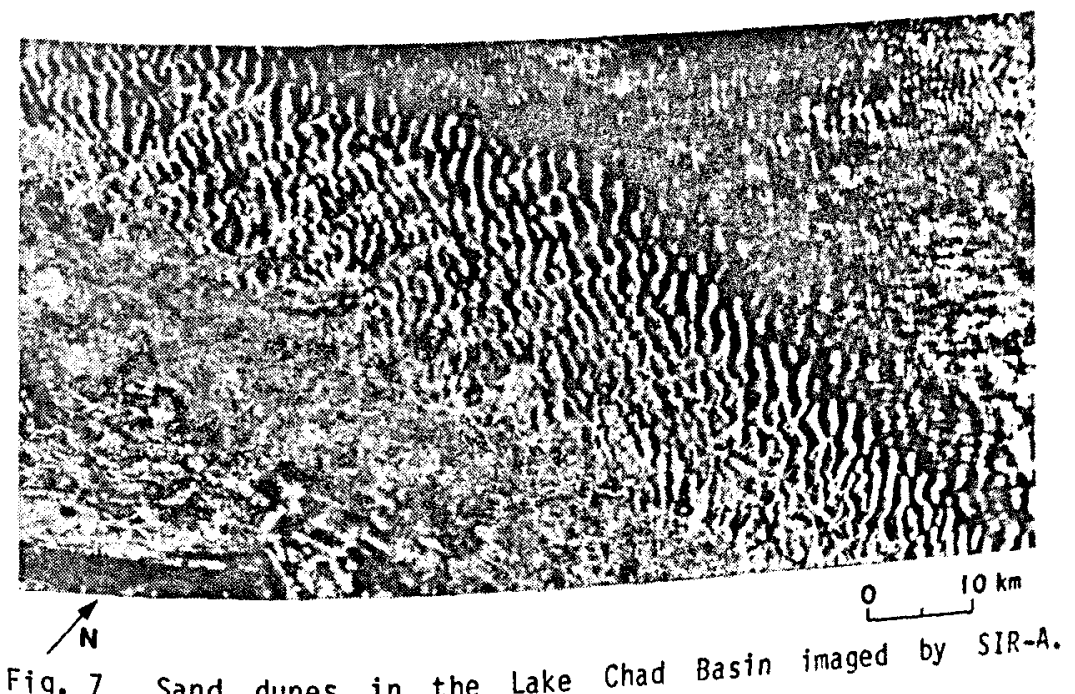

Fig. 7 Sand dunes in the Lake Chad Basin imaged by SIR-A. 
penetration occurs in very dry soils, frozen soils, or dry snow cover.

The penetration capability of the imaging radar was most dramatically illustrated with the SIR-A images over southwestern Egypt.8,21 In a large area of northeast Africa, the surface is covered with a a sand sheet with thickness up to a few meters, thus hiding most of the details of the local morphology. In addition, that area forms the core of one of the most arid regions on Earth. The environmental conditions are such that rain occurs at a rate of once every $40-50$ years and the soil moisture is less than $0.5 \%$.

Figures 9 and 10 show the comparison between the Landsat image and the radar image of part of the area. The radar shows a wealth of morphologic details that seem to indicate extensive past fluvial activity over a large region. Field work in the area 8 confirmed that the fluvial activity did occur in the past and its surface signature is covered by a sand sheet with a thickness ranging from about a half a meter to a few meters. Modeling of radar wave interaction with such a covered surface also showed that the subsurface interface should be visible on the radar image. 21 In actuality, the presence of the dry sand layer tends to enhance the radar capability to image the subsurface interface due to wave refraction at the surface.

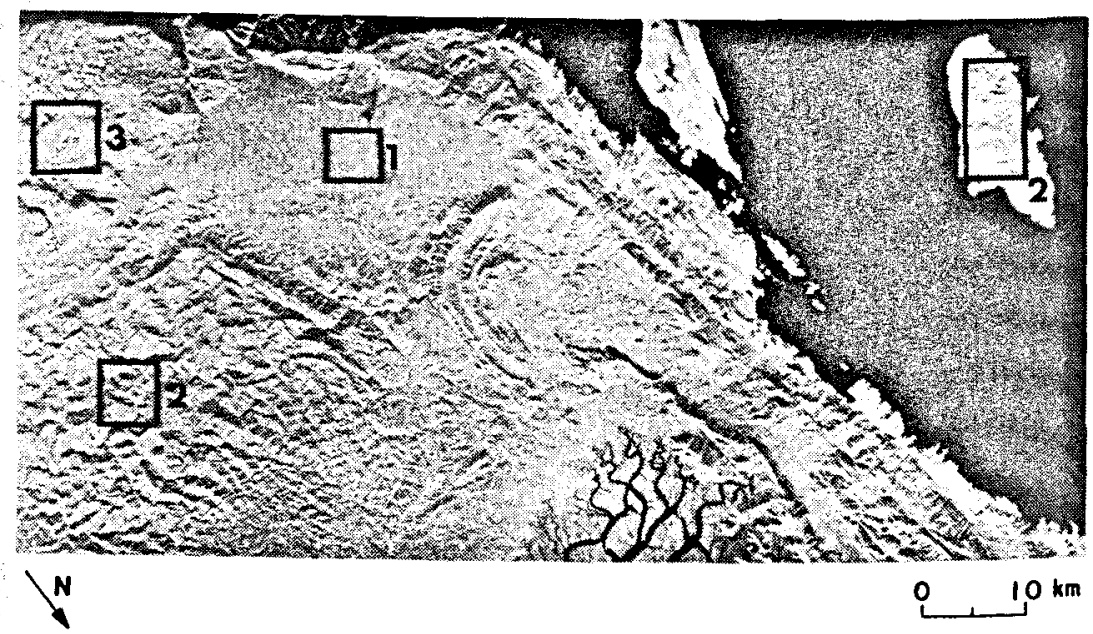

1 Alluvial Deposits 2 clastic Terrain 3 carbonate Terrain

Fig. 8 SIR-A image of southeastern Vogelkop region of Indonesia Showing three of the six types of lithology that were mapped by 


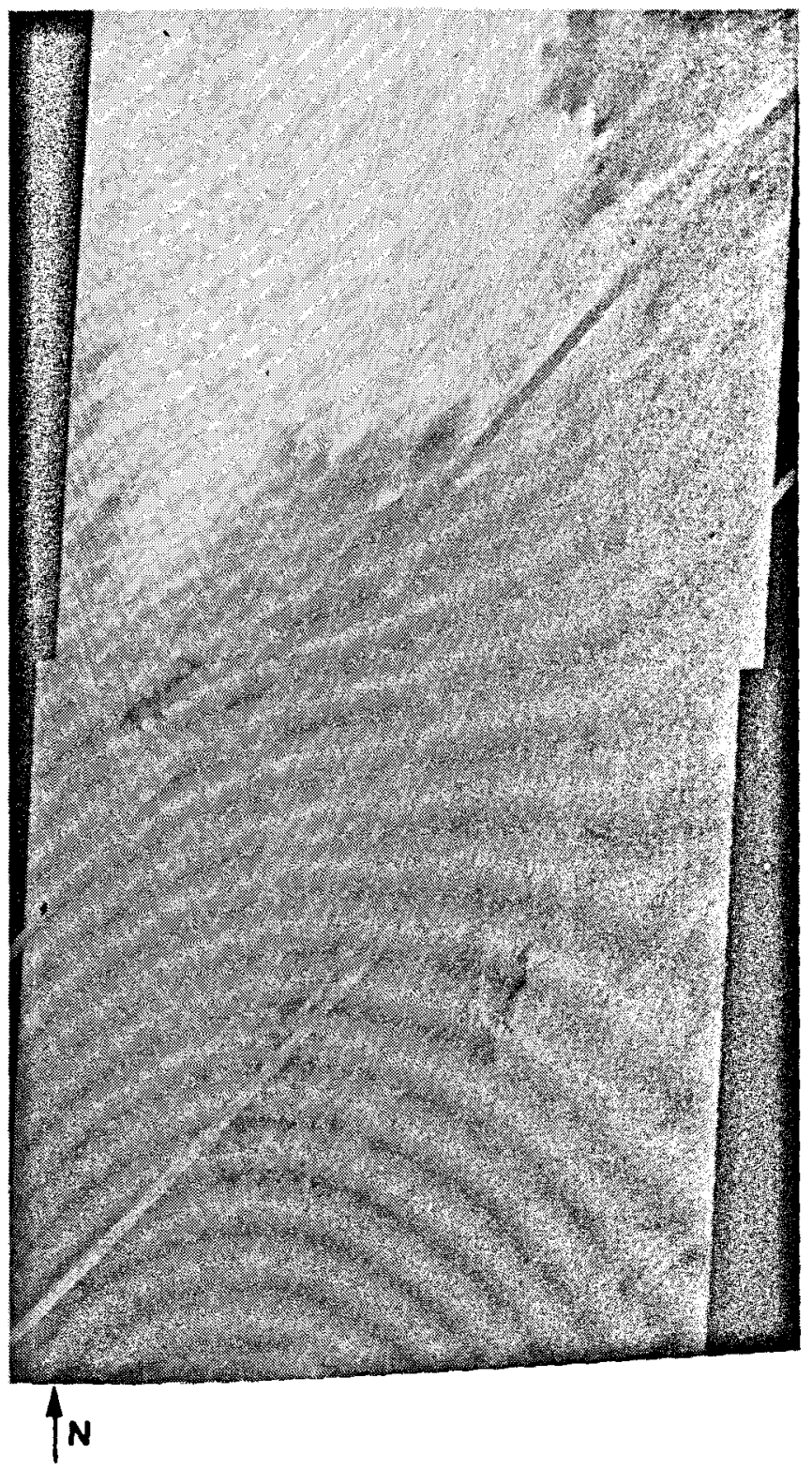

Fig. 9 Landsat image over Egypt.

The subsurface imaging capability was also observed on the Seasat radar images of arid areas in southern California where geologic dikes covered by a layer of dry alluvium were clearly imaged. 22 


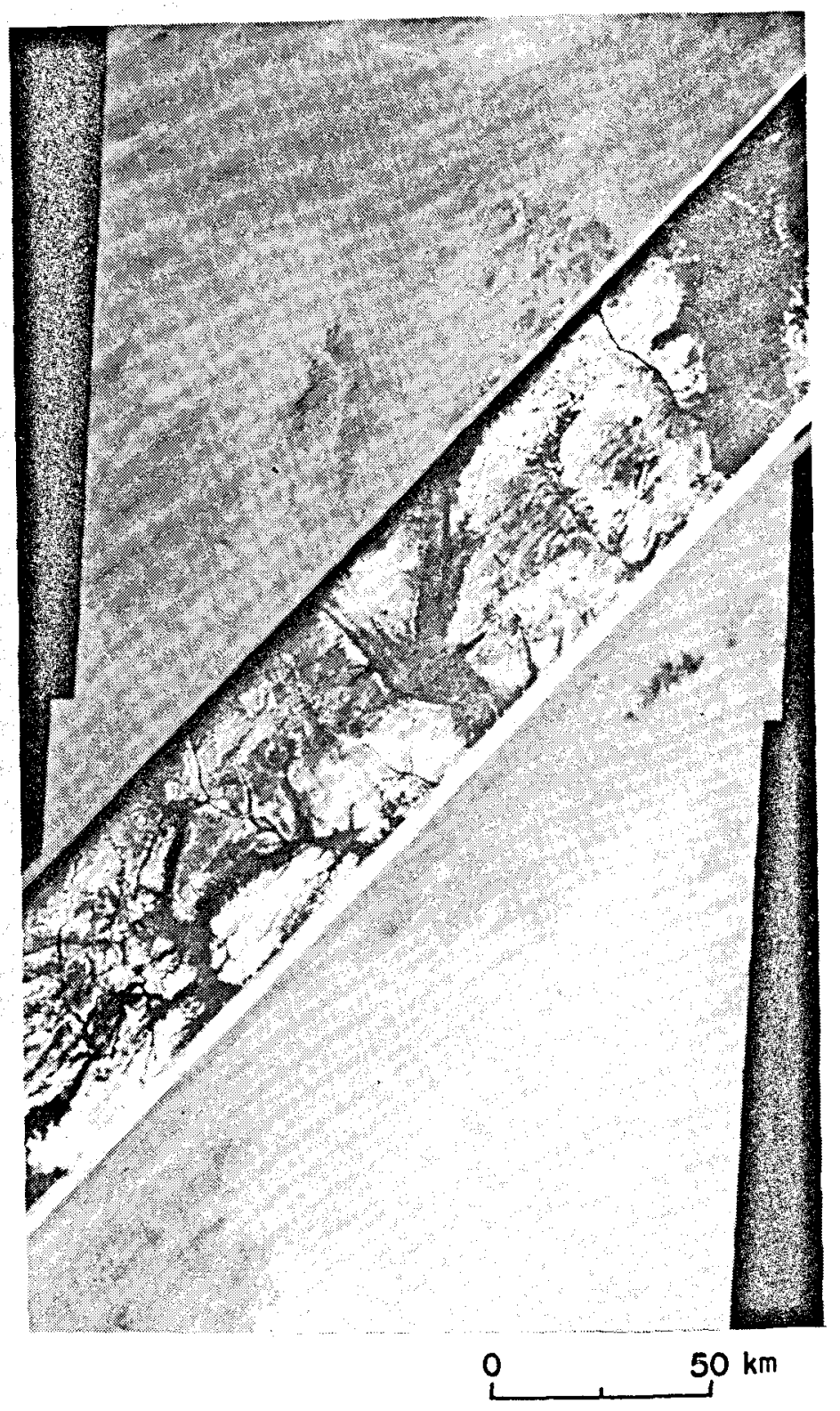

Fig. 10 SIR-A image swath of same region shown in Fig. 9 showing buried river and stream channels.

\section{Vegetation and Soil Moisture Mapping}

In vegetated regions, the radar backscatter is controlled primarily by the plant structure, height, wetness, and large-scale geometric properties such as the row direction of fields and orchards. It is not well known to what 
extent radar actually penetrates the vegetation. The extent of penetration is highly dependent on the radar wavelength, the polarization, and incidence angle, as well as the physical properties of the vegetation canopy.

Radar imagery is very sensitive to the wetness of an area due to large changes in the dielectric constant of soil and vegetation with the addition of water. Soil moisture detection may be an important application of radar once calibrated imagery is available. On Aug. 16, 1978, Seasat acquired the image shown in Fig. 11 in Ames, Iowa. Prior to acquisition of the image, a large convective storm front and several isolated storm cells passed through the areas depositing rain along the paths. The lighter region of the image indicates areas where the rain was deposited and the surface was still moist at the time of acquisition of the image (see Fig. 11 and Ref. 5).

One of the more dramatic images acquired by SIR-A was of the Maranhao Province of Brazil where extensive clearcutting of the Amazon forest is underway. Figure 12 shows the dense Amazon forest, which was a very uniform bright radar return, and the large dark blocks of clearcut regions. The smooth, level clearcut regions, which produce a dark image tone, make the clearcut areas easily mappable.

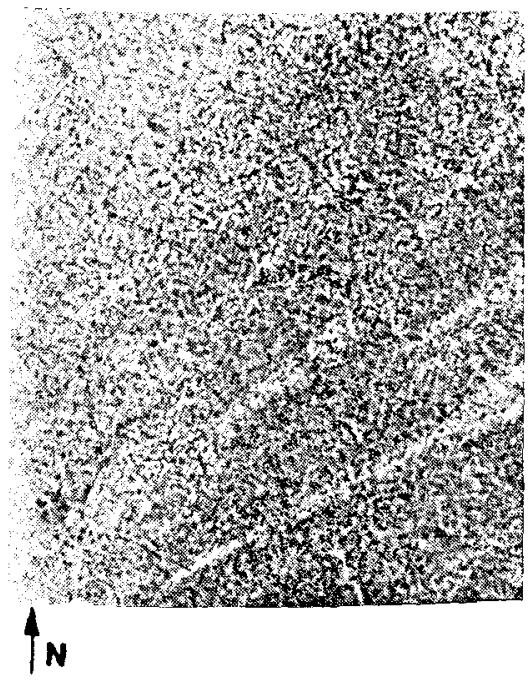

(a)

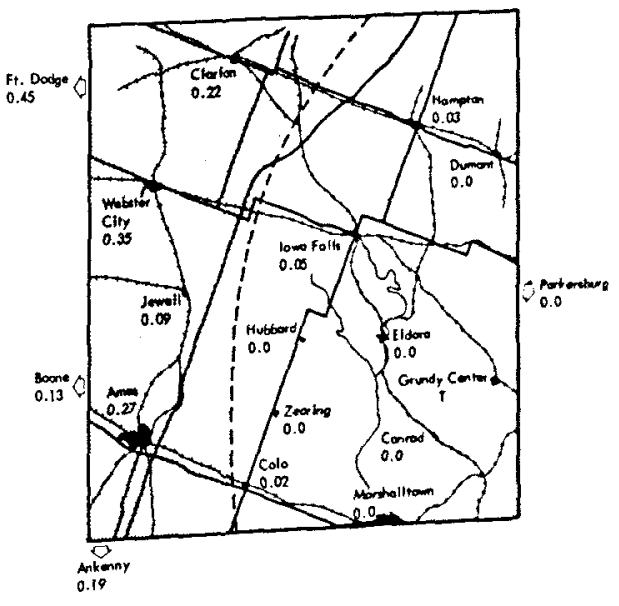

(b)

Fig. 11 a) Plains of central Iowa imaged by the Seasat SAR just after a rain storn, Aug. 16, 1978. b) Map of the region in a) showing the location of the wet surface (from Ref. 39). 


\section{Applications in Ocean and Polar Ice Studies}

In oceanographic applications, the imaging radar sensor has a unique and essential characteristic: the capability to acquire high-resolution images of the surface regardless of cloud cover and at any time of the day or night. This characteristic is essential because of the dynamic nature of almost all the features on the ocean surface. A review of spaceborne imaging radar applications in oceanography is given in Refs. 4 and 23.

The radar sensor provides an image that is representative of the surface backscatter characteristics. In the case of the ocean, the backscatter is controlled by the small-scale surface topography: the short gravity and capillary waves, which scatter the radar energy by the Bragg scattering mechanism, and the local tilt of the surface, which is due to the presence of large waves and swells. Thus, the SAR is capable of imaging surface and near-surface phenomena that affect the surface roughness directly or indirectly. These phenomena include surface waves, internal waves, currents, weather fronts, wind or oil slicks, and eddies. In this section we discuss examples of ocean features that have been observed with the Seasat and SIR-A SAR data.

The Seasat SAR provided for the first time a synoptic high-resolution view of large ocean areas; and in some

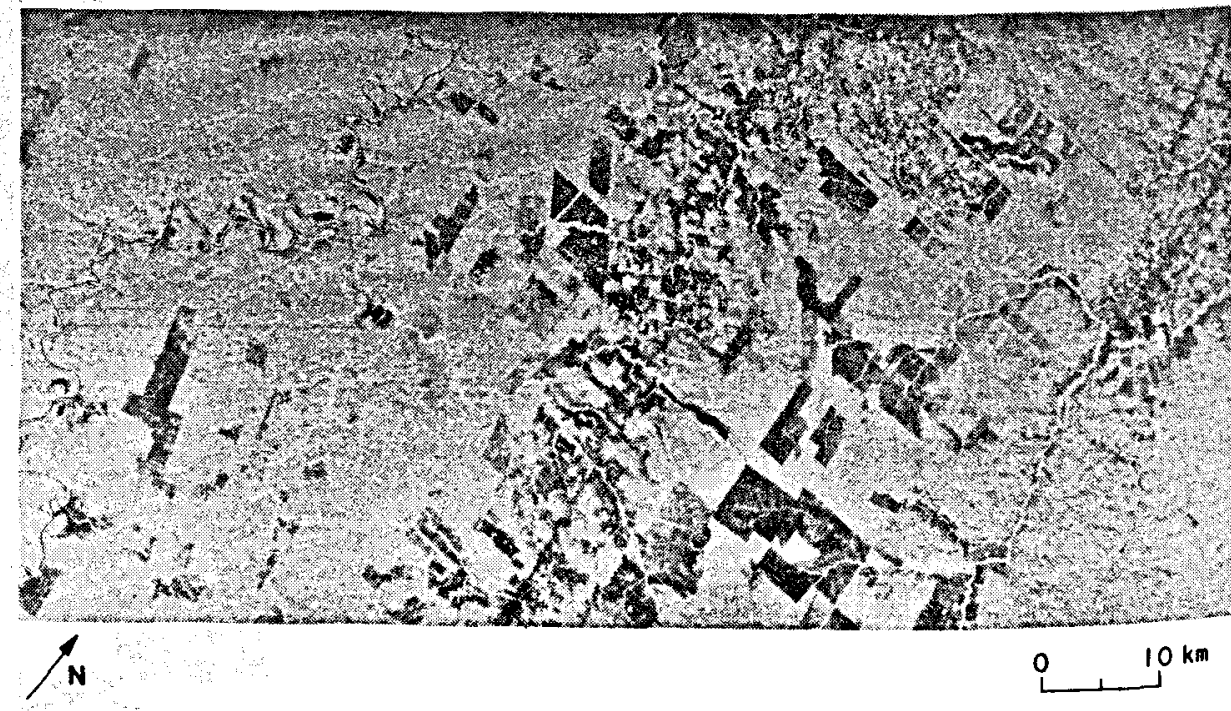

Fig. 12 SIR-A image of the Maranhao Province of Brazil showing extensive clearcutting of the Amazon Forest. 
cases, it provided repetitive observations of the same region every 3 days. The SIR-A provided only a very limited ocean coverage.

Surface waves are visible on the radar image as a periodic regular change in the image tone (Fig. 13). The spatially periodic change in the surface-coherent backscatter cross section is a result of three surface effects that are modulated by the presence of a propagating surface wave or swe11: local slope; the intensity and bunching of small gravity and capillary waves; and the wave orbital velocity, which affects the phase of the returned echo. The relative importance of these three effects is the topic of current research (see Refs. 4, 24-27).

Figure 13 shows a Seasat image of ocean surface waves acquired over the northeastern Atlantic near the Shetland

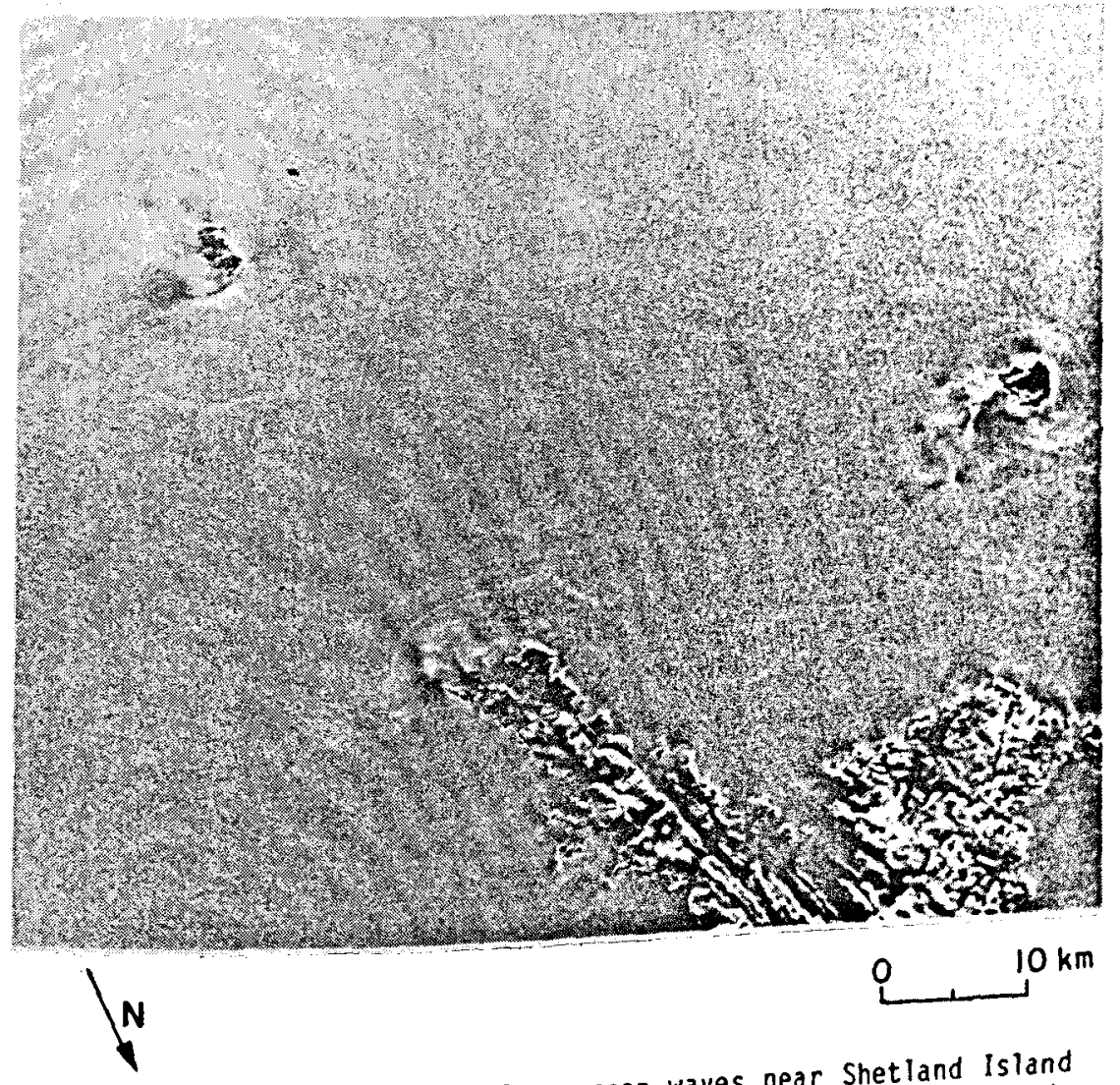

Fig. 13 Seasat image of surface ocean waves near Shetland lsland England. The swell had a wavelength of $300 \mathrm{~m}$. The two diffraction of are Foule and Fair 1sle. Observe the refraction and the swell near the coast. 
Islands. The surface waves had a wavelength of about 300 $m$, and the refraction patterns near the coast are clearly visible. This Seasat image was acquired in $14 \mathrm{~s}$. Thus it represents an almost instantaneous snapshot of the wave pattern over this $100 \times 100 \mathrm{~km}$ region.

Figure 14 shows internal waves in the Gulf of California near the island of Angel de la Guardia. These waves are observed as a result of their surface manifestations and their effect on the surface roughness. The rather large currents associated with these waves modify the capillary ultragravity surface-wave spectrum overlying the oscillations. The exact mechanisms by which the modifications take place are still the subject of discussion, but at least two hypotheses have been advanced. 28 According to the first hypothesis, the high velocity of surface water arising from the internal wave amplitude can sweep surface oils and materials together to form a smooth strip near regions of surface water convergence. The second mechanism predicts that capillary and ultragravity wave energy is concentrated in the convergence zone by surface-current stress, which then becomes a region of enhanced roughness rather than a smooth area as with the first hypothesis. When such smooth and rough regions are illuminated away from normal incldence and then viewed at nonspecular angles, the smooth region would appear darker and the rough one brighter than the normal sea surface. This geometry is the same for both imaging radar and multispectral (including optical) sensors.
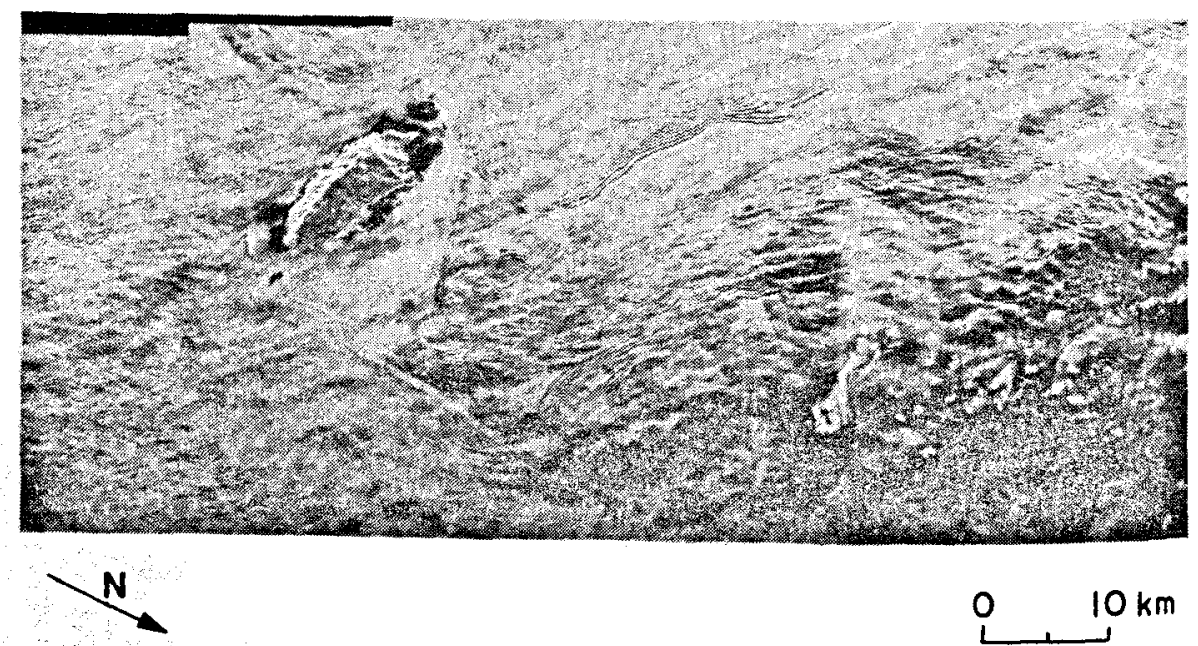

Fig. 14 Seasat image of internal waves near the island of San Nicolas off the coast of California. 
Internal waves are usually observed on the radar image as a wave packet that consists of a series of convex strips, with the spatial periodicity becoming shorter toward the center of curvature. The length of the crest may range up to many tens of kilometers. The leading wavelengths are on the order of 1-2 km and decrease monotonically toward the rear. They usually occur in groups or packets and they have been observed in numerous places along the western and eastern coasts of North America. Similar observations have been conducted with aircraft SAR 29 and optical sensors. 30 on some Seasat single swaths, more internal waves could be observed than the total number observed during dozens of aircraft flights over a period of 5 years. This illustrates the new insight that resulted from the Seasat SAR experiment on the extent and rate of occurrence of certain dynamic ocean phenomena.

$\mathrm{Fu}$ and $\mathrm{Holt}^{6}$ conducted a study of the internal waves in the Gulf of California as observed with the Seasat radar. They studied the temporal variability of the internal wave field over a 3-week period. They found that the number of observed wave groups is highly correlated with the strength of the local tides and that the visiblity of the waves on the radar image is somewhat related to the strength of the surface wind. Stronger winds tend to increase the ocean surface roughness over large areas, thus making the roughness modulation due to the internal waves harder to detect.

An interesting phenomenon which was observed with the Seasat radar is shown in Fig. 15. The different patterns observed in the shallow waters around Nantucket Island correlate very closely with the bottom bathymetry. The radar waves do not penetrate the ocean surface sufficiently to sense the bottom topography. The most likely interpretation is that the change in the thickness of the water column modulates the velocity of the near-surface current. This in turn modulates the ocean surface roughness that is the main physical parameter that the radar is sensing. Thus, indirectly, the radar image reflects the bottom topography.

Other features observed on radar images include current boundaries, eddies, and vessels.

Polar Ice and Glaciology Applications

Spaceborne imaging of the polar ice cover is of Spaceborne imaging of the polar mapping of the ice-
particular interest in two areas: 1) mastribution of the
cover motion and extent and spatial distrion open water channels and 2) determination of ice floes' age. 


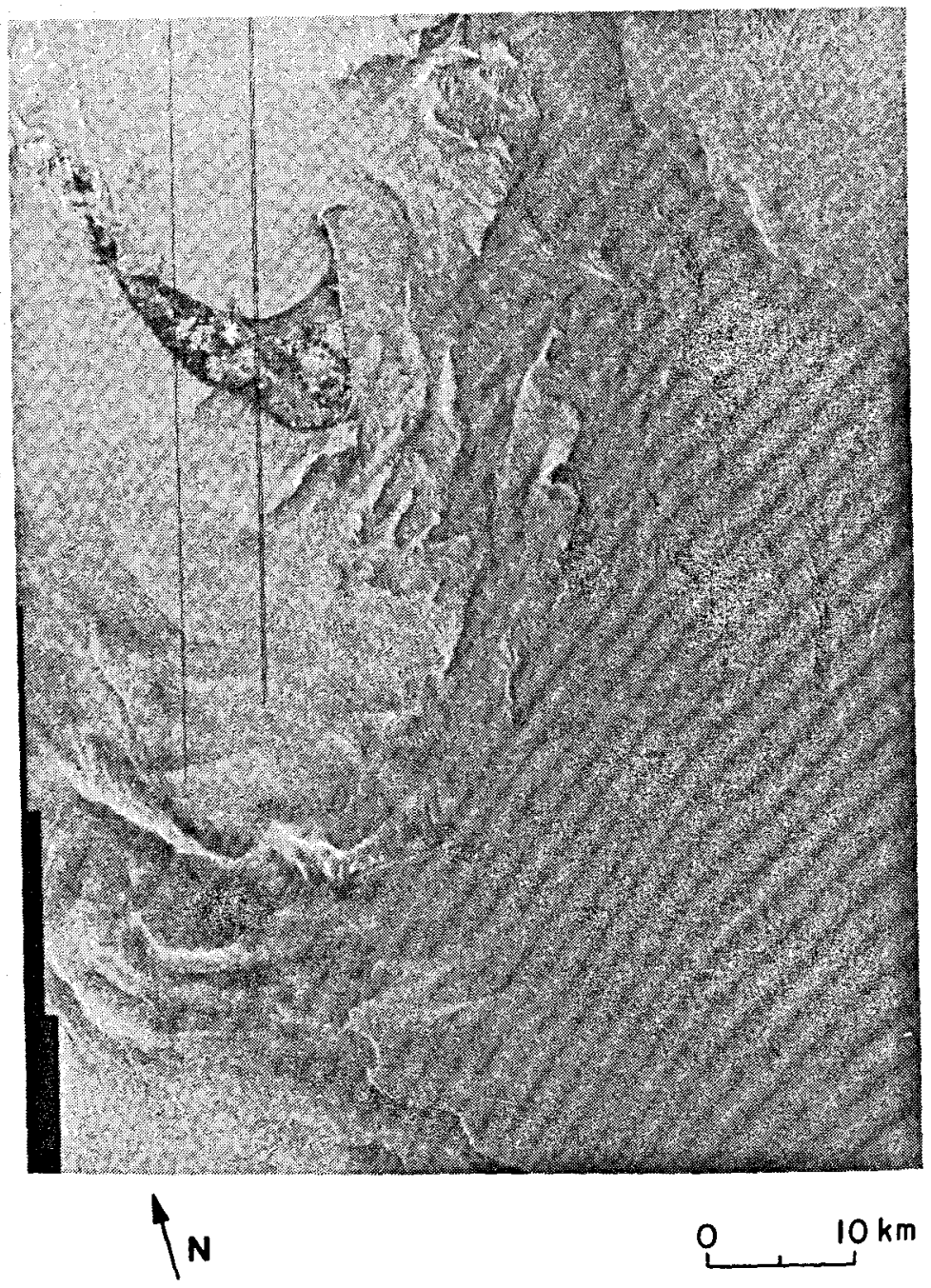

Fig. 15 Seasat image of the Nantucket Island region. The island is visible in the upper left corner of the image. Most of the other patterns observed on the ocean surface reflect the bottom topography in this shallow region.

A spaceborne imaging $S A R$ is the ideal sensor for mapping the spatial distribution, extent, and motion of ice. The radar allows repetitive observation all through the year. Global coverage every 3-4 days can be easily achieved at the polar regions. For this application, the main observable characteristics are the shape, size, and distribution (including accurate spatial location) of the ice features. Figure 16 shows an example of a Seasat image of an ice region which was observed over a period of about 


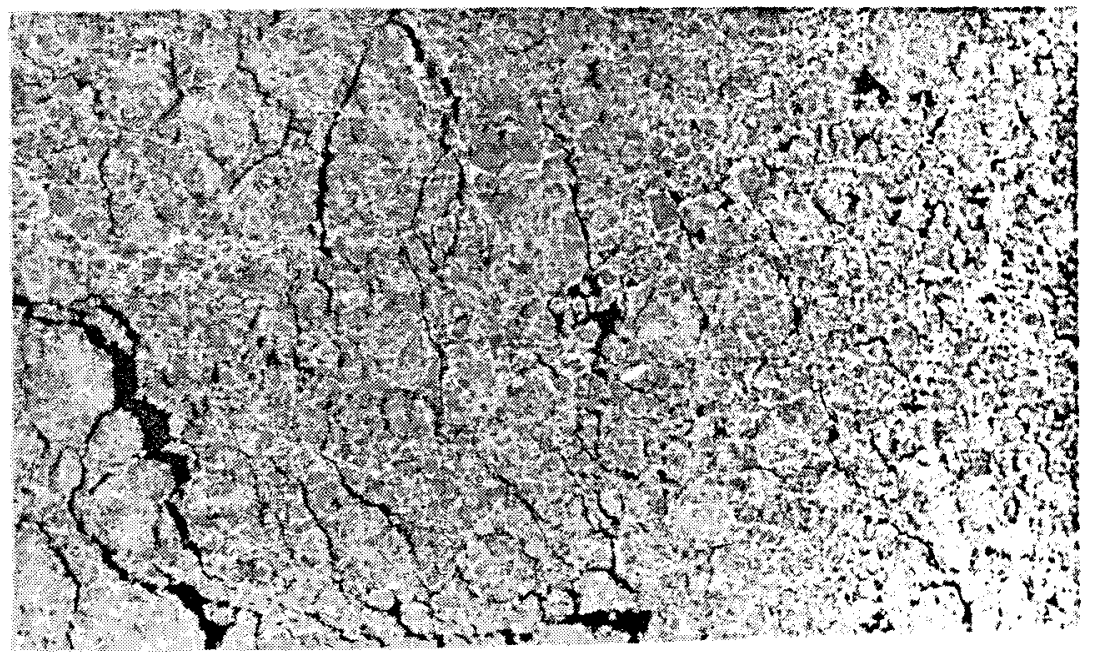

October 1, 1978

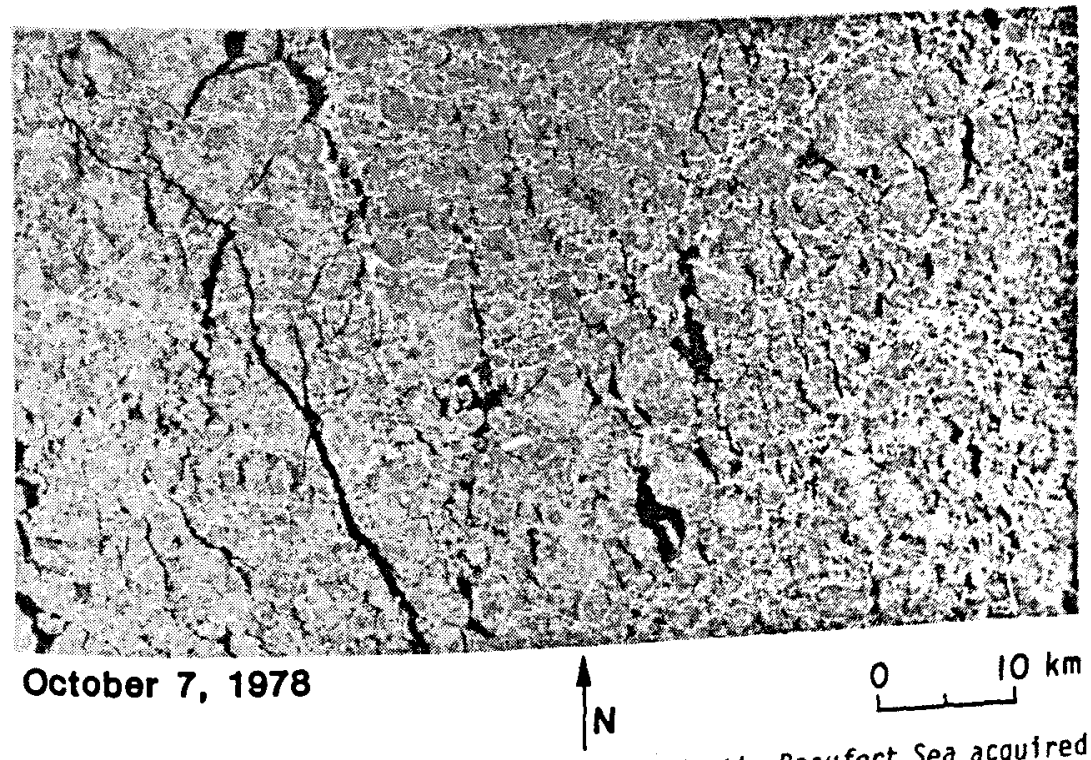

Fig. 16 Seasat image of polar ice floes in the Beaufort Sea acquired 6 days apart. The bright section is most likely a stranded ic

2 months in the summer of 1978. Figure 17 shows the motion of that region during that time period.

To be able to determine the ice type and age, a better understanding of the wave/surface interaction mechanisms is required. At the present time, it seems that a multiparameter radar system might be necessary in order to classid, or many years old. 


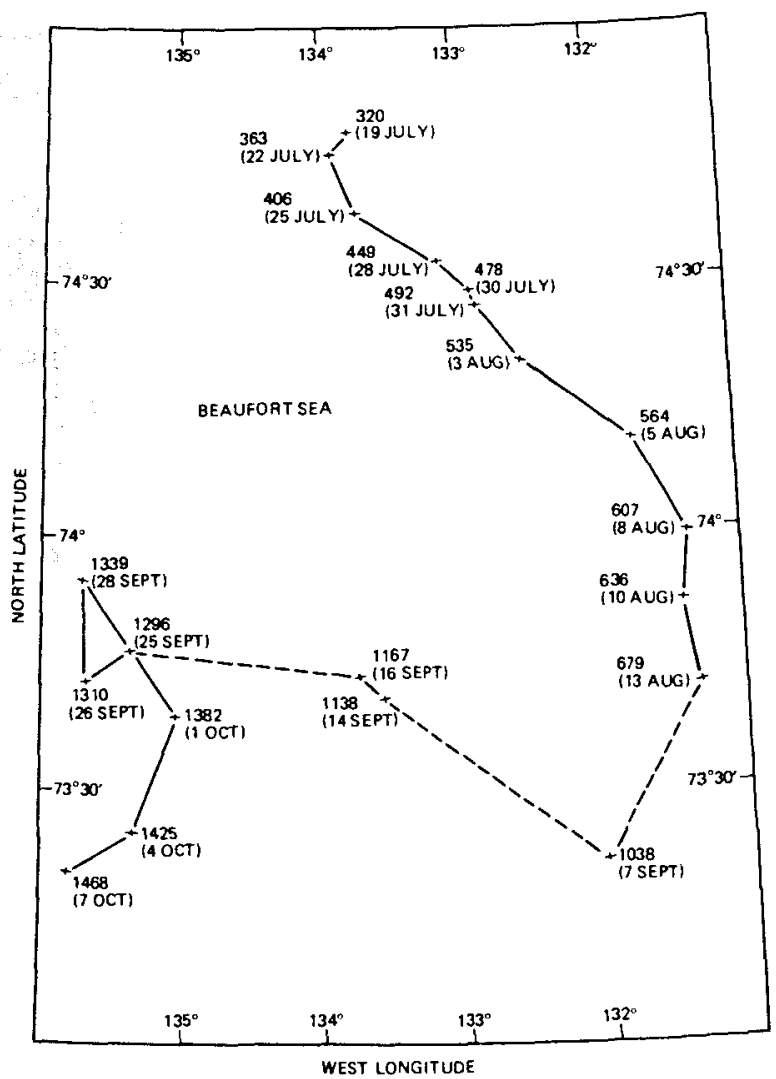

Fig. 17 Trace of the stranded iceberg shown in Fig. 16.

Figure 18 is the Seasat SAR image of the Malaspina Glacier in southeastern Alaska. The ice floe patterns are observed because of the folded moraines, which usually have different roughness characteristics from the surrounding ice.

\section{Technology of Spaceborne Radar Sensors}

A spacebonre radar system can be divided into four major elements (Fig. 19). The antenna radiates the electromagnetic signal generated by the $r f$ (radio frequency) electronics toward the surface to be image and it collects the backscattered energy intersecting it. The collected energy is sent to the $r f$ electronics for detection and conversion into a form that can be handled by the data system. The data system formats the data and either records onboard (digital or analog) or transmits to the ground via a data link. On the ground the data are pro- 


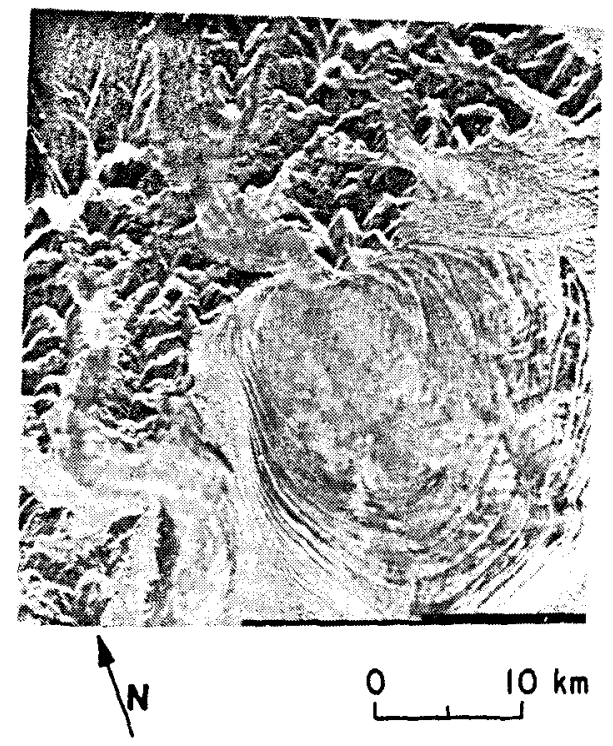

Fig. 18 Seasat image of the Malispina glacier, Alaska. The ice floe pattern is visible as a series of bright and dark curvilinear regions corresponding to the areas of different roughness.

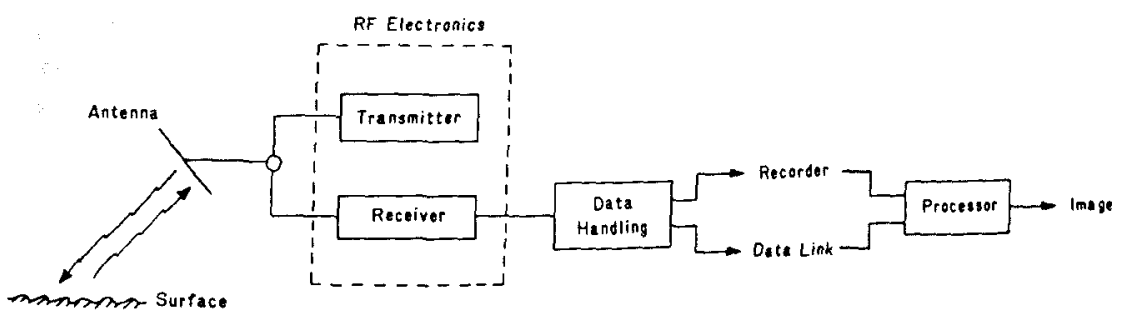

Fig. 19 Basic elements of a spaceborne radar systen.

cessed, either optically or digitally, to form the synthetic aperture and generate the radar image. In this section we give a description of the Seasat SAR, SIR-A, and SIR-B. Details of the Seasat SAR are based on the articles by Jordan 31 and Elachi et al. 32

\section{The Seasat SAR}

The first spaceborne imaging radar was launched on June 28, 1978, on Seasat, a free-flying spacecraft carrying a variety of instruments designed for observation of the oceans. The instrument package included a microwave radiometer, a visible/infrared radiometer, and three microwave radars, one of which was a synthetic aperture radar. Seasat's mission ended on 0ct. 10, 1978, when a massive 
short circuit in its electrical system occurred. During its 105 days in orbit, however, the Seasat SAR retrieved imagery of more than $100 \times 10^{6} \mathrm{~km}^{2}$ of the Earth's surface and provided the first high-resolution SAR images of our Earth.

The Seasat SAR sensor system, shown in Fig. 20, consists of a planar array antenna, a transmitter/receiver $r f$ sensor, an analog data link, a data formatter, and a highdensity digital recorder subsystem that outputs the "signal record". The characteristics of the sensor are summarized in Table 1. It was designed to provide continuous strips of radar imagery with a $100 \mathrm{~km}$ swath at a resolution of 25 $\mathrm{m}$ from an orbital altitude of $795 \mathrm{~km}$. Because the radar data were directly linked to a limited number of specially equipped ground stations, the coverage was limited to the central and northern American hemisphere, western Europe and North Atlantic, the North Pacific, and the northern polar regions.

Antenna. The Seasat SAR antenna system consists of a $10.74 \times 2.16 \mathrm{~m}$ phased-array system deployed after orbit insertion. This deployed antenna is configured to fly with the long dimension along the spacecraft-velocity vector and bore-sighted at an angle of $20.5 \mathrm{deg}$ from the nadir direction in elevation (cone) and $90 \mathrm{deg}$ from the nominal spacecraft-velocity vector (clock). At a nominal $20.5 \mathrm{deg}$ look angle from nadir, a total beamwidth in elevation of $6.2 \mathrm{deg}$ is required to illuminate a $100 \mathrm{~km}$ swath on the Earth's surface from a $795 \mathrm{~km}$ high orbit. Thus, the antenna cross-track dimension is $2.16 \mathrm{~m}$ to limit the radiation to these sets of angles. The area illuminated on the surface

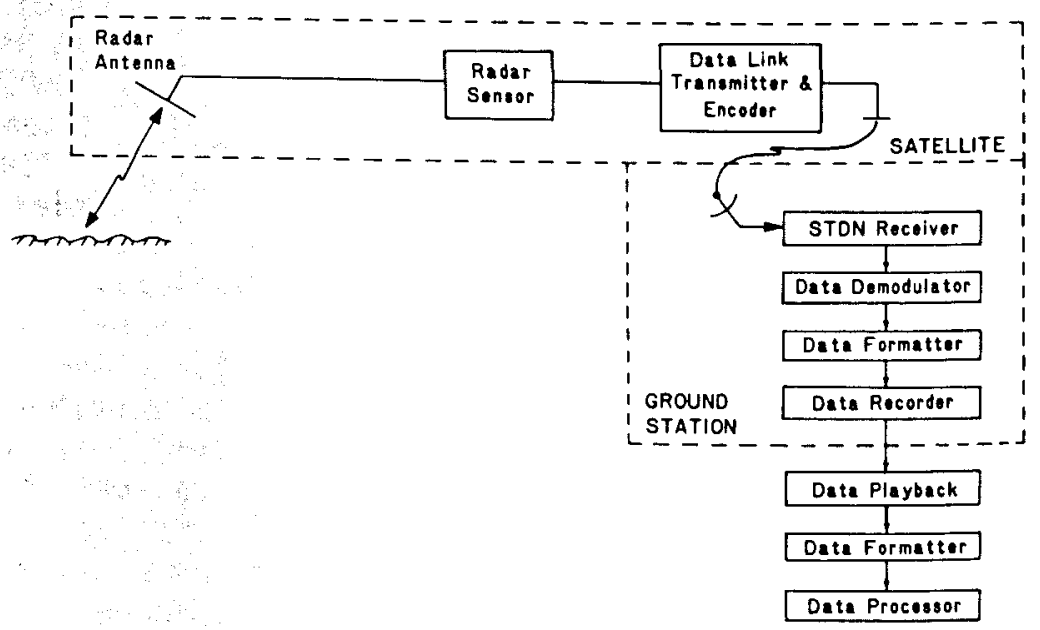

Fig. 20 Basic elements of the Seasat SAR system. 
Table 1 Characteristics of Seasat SAR, SIR-A and SIR-B

\begin{tabular}{llll}
\hline \multicolumn{1}{c}{ Parameter } & Seasat & SIR-A & SIR-B \\
\hline Orbital altitude, km & & & \\
Orbital inclination, deg & 108 & 259 & $\sim 220$ \\
Frequency, GHz & 1.28 & 38 & 57 \\
Wavelength, cm & 23.5 & 1.28 & 1.28 \\
Polarization & $H H$ & $H H$ & 23.5 \\
Look angle(s), deg & 20.5 & 47 & $H H$ \\
Swath width, km & 100 & 50 & $15-60$ \\
Peak power, kW & 1 & 1 & $20-60$ \\
Antenna dimensions, m & $10.74 \times 2.16$ & $9.4 \times 2.16$ & $10.74 \times 2.16$ \\
Bandwidth, MHz & 19 & 6 & 12 \\
Number, of looks & 4 & 6 & 4 \\
Azimuth resolution, m & 25 & 38 & 25 \\
Range resolution, m & 25 & 38 & $58-17$ \\
Optical data collection, $h$ & 0 & 8 & 8 \\
Digital data collection, $h$ & 40 & 0 & $\sim 8$ \\
Digital link capability, & 110 & $\mathrm{~N} / \mathrm{A}$ & 46 \\
megabit & & & \\
Coverage, xlo6 km2 & 100 & 10 & $\sim 10$ \\
\hline
\end{tabular}

of the Earth is $240-340 \mathrm{~km}$ to the right of the subspacecraft point. The antenna elements in elevation are weighted to limit side lobes in the cross-track direction. The minimum antenna along-track length is limited by a desire to keep azimuth sampling ambiguities to an acceptably low level, while the maximum along-track length is determined by the requirement to illuminate a sufficientiy large patch of terrain to allow processing of the data to achieve $25 \mathrm{~m}$ resolution in azimuth with four looks.

These two requirements limit the antenna length along the velocity vector to between 10.5 and $14 \mathrm{~m}$. The $10.74 \mathrm{~km}$ antenna length was dictated by the available volume within the satellite shroud. The level of integrated abiguities in azimuth was estimated to be between -18 and $-24 \mathrm{~dB}$, depending on the selected pulse repetition frequency and processor bandwidth in azimuth.

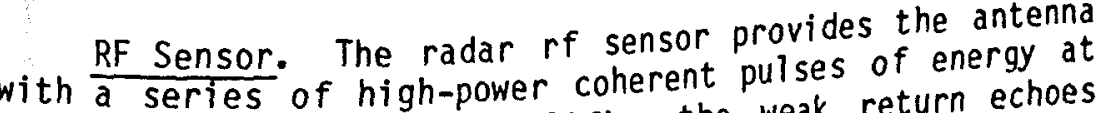
$L$ band (1.275 GHz) and amplifies the weak return echoes collected by the antenna. The bandwidth of the pulses was $19 \mathrm{MHz}$, which provided a ground range resolution of $25 \mathrm{~m}$. The signal was both transmitted and received horizontally in polarization (HH) with a pulse repetition frequency (PRF) of 1463-1640 pulse/s. The radar sensor consists of 


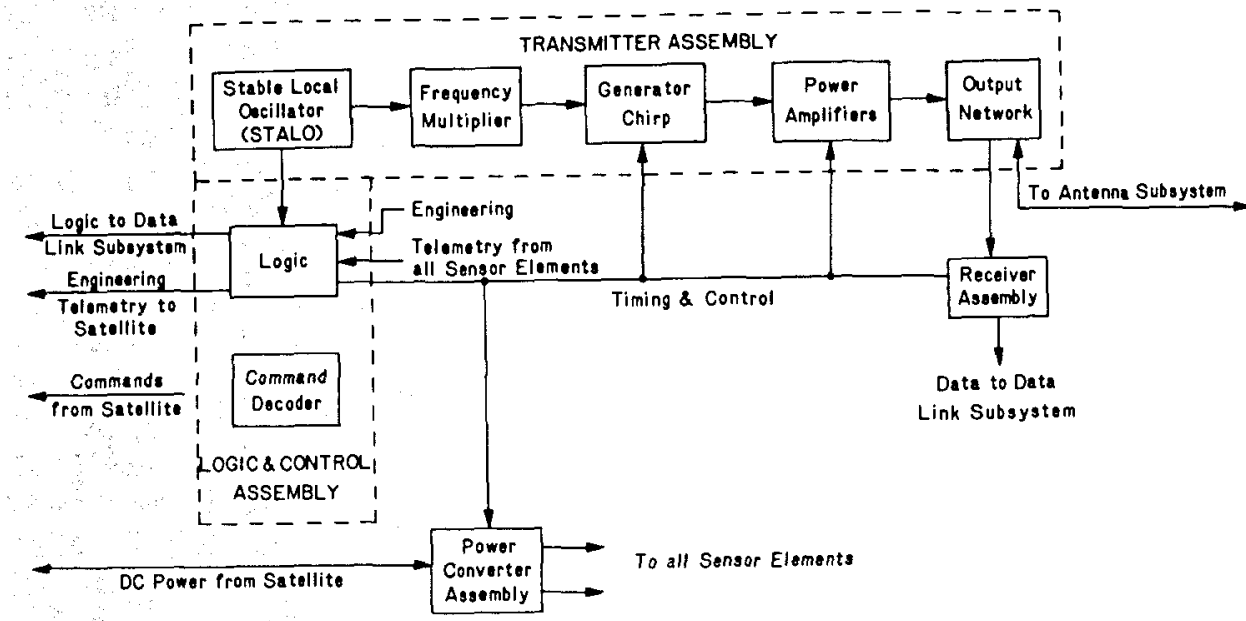

Fig. 21 Block diagram of the Seasat radar rf sensor.

four subassemblies: transmitter, receiver, logic and control, and power converter. A diagram of the sensor is shown in Fig. 21 and the principal sensor parameters are tabulated in Table 2.

To obtain an adequate signal-to-noise ratio (SNR) from a system whose range resolution is $25 \mathrm{~m}$ on the surface and that utilizes a solid-state transmitting device, it is necessary to use a long transmitted pulse and pulse-compression techniques to reduce the peak-power requirement. The output of the transmitter assembly is, as a result, a linearly swept frequency-modulated pulse (or chirp) having a 634:1 compression ratio. It is generated in a surface acoustic wave (SAW) device located in the chirp generator subassembly of the transmitter assembly. The output of the transmitter is coupled to the antenna subsystem through an output combiner. A portion of the output (leakage) is also impressed on the receive input, where a load is placed in the circuit each time the transmitter operates. This prevents the leakage pulse from burning out the input stage of the receiver.

Echo returns are coupled into the receiver assembly through the output network in the transmitter. Because the echo's intensity is expected to vary in proportion to the variation of antenna gain with angle, a sensitivity time control (STC) has been incorporated in the receiver. The STC action, initiated by satellite stored commands, linearly decreases the receiver gain by $9 \mathrm{~dB}$ during the first half of the return-echo period and then increases the gain until 
Table 2 Sensor electronics subsystem

\begin{tabular}{ll} 
Center frequency & $1274.8 \pm 0.31 \mathrm{MHz}$ \\
Bandwidth & $19.05 \pm 0.05 \mathrm{MHz}$ \\
STALO frequency & $91.059 \pm 0.0022 \mathrm{MHz}$ \\
STALO stability & $3 \mathrm{parts} / 10^{10}$ in $5 \mathrm{~ms}$ \\
Pulse width & $33.9 \pm 0.8 \mathrm{~s}$ \\
Peak power & $1000 \mathrm{~W}$ nominal \\
Pulse envelope rise time & $90 \mathrm{~ms}$ \\
Pulse envelope fall time & $90 \mathrm{~ms}$ \\
Pulse repetition frequencies & $1464,1540,1580,1647 \pm 0.1$ \\
Noise temperature & $650 \mathrm{~K}$, nominal \\
Receiver gain control steps & 8 \\
Gain control step spacing & $3 \pm 0.3 \mathrm{~dB}$ \\
Gain control range & $77-98 \mathrm{~dB}$ \\
STC gain variation & 9 \\
Receiver gain flatness & $\pm 0.33 \mathrm{~dB}$ \\
Receiver gain stability (0-60 & $\pm 1.0 \mathrm{~dB}$ \\
Receiver bandwidth $(3 \mathrm{~dB})$ & $22 \pm 0.2 \mathrm{MHz}$ \\
Receiver phase ripple & $4.0 \mathrm{deg} \mathrm{dev}$. from quadratic \\
Transmitter FM slope & $0.5622 \mathrm{MHz} / \mathrm{s}$ \\
Transmitter phase response & $3 \mathrm{deg} \mathrm{rms}$ \\
\hline
\end{tabular}

the end of the echo has been received. The application of the STC results in a nearly uniform signal (echo) return for a uni form scattering field and, as a result, the dynamic range required to transmit the resultant data to Earth is reduced by $9 \mathrm{~dB}$.

The sensor/receiver output is sent to the data link dlong with timing and frequency references derived from the SAR system local oscillator (STALO). The STALO generates a very stable (in frequency) signal at a nominal frequency $f_{s}$ $(91.059 \mathrm{MHz})$, a portion of which is delivered to the multiplier assembly. Another portion of this signal is used to derive both square-wave clock and sine-wave signals at $f_{s} / 3$, which are used in synchronizing some sensor electronics subsystem functions. The frequency multiplier assembly provides signals at $f_{s} / 3$, which are used in synchronizing other sensor electronics subsystem functions. The frequency multiplier assembly provides signals at 3,9 , The 3 and $18 \mathrm{fs}_{\mathrm{s}}$ signals are delivered to the chirp generator where, along with a portion of the STALO signal, $f_{S}$, they are used to generate the linear $F M$ pulse (chirp) signal at the carrier frequency of $14 \mathrm{fs}$. The signal at $9 f_{s}$ and a portion of the signal at $f_{s}$ are delivered directly to the data-link subsystem along with a 
signal derived from the PRF event, which divides the interpulse interval into 4096 sectors.

The remaining two assemblies in the sensor electronics subsystem are the logic and control as well as the power converter. They provide the primary electrical interface with the satellite. The logic and control assembly receives commands from the satellite, decodes them, and causes the sensor electronics subsystem to assume one of a number of operating modes. In addition, the logic and control interfaces between the satellite and the intrasubsystem engineering telemetry. The power converter assembly provides the stable, isolated power required by all the SAR subsystems.

Data Link Subsystem. The purpose of the data link subsystem is to transmit the radar echo to the ground for digitization, storage, and subsequent processing. The link also maintains the phase and time references necessary to the processing function, thus providing a unity transfer function. The chosen implementation technique was a linear S-band modulator/transmitter/receiver/demodulator combinaation. This choice was governed chiefly by the available frequency spectrum/bandwidth.

In addition to the basic requirement for linearity to preserve the SAR coherent information, the inclusion of necessary phase and timing signals placed an additional burden on the linear property of the link. The data link subsystem performed the following functions:

1) Translated the L-band echo return to $S$ band.

2) Orthagonally combined the offset video with both PRF and STALO reference.

3) Amplified the result linearly (with negligible phase error) for transmission.

On the ground, the data link subsystem:

1) Translated the composite $S$-band signal to an offset video frequency centered at $11.25 \mathrm{MHz}$. craft local oscillator. signal.

3) Removed the link-induced Doppler from the composite video.

4) Reconstructed the PRF and STALO signals from the

Ground Station Subsystem. The Seasat SAR system required unique equipment at the ground receiving station. Only three U.S. stations (Fairbanks, Goldstone, and Merritt Island), one Canadian station (Shoe Cove), and one British 
station (0ak Hangar) were equipped to receive the SAR data. The SAR operations were limited to the time periods when the satellite was in view of one of those stations.

The ground station subsystem consists of a data formatter and a high-density digital recorder. Upon the receipt of a trigger signal from the data link subsystem demodulator assembly, the data formatter accepts and digitizes the analog offset video signal furnished by the demodulator. Digitization occurs only diring the period $(\sim 300 \mu \mathrm{s})$ when the SAR video return is expected. The resulting thirteen 680 samples, which are generated at a rate of 227 megabit/s, are temporarily stored within the data formatter. Information on the operational status of the data formatter and the demodulator is also collected and retained.

The video samples, the status information, and the GMT time are formatted and sent to the high-density digital recorder (HDDR) at a rate of about 113 megabits/s. The HDDR records this high-rate stream on 1 in. width magnetic tape. Recording uses 40 (of 42) parallel tracks on the tape at a recording speed of $150 \mathrm{in} / \mathrm{s}$. Parity is included on each track and timing information is carried on one of the remaining tracks.

The output "signal" tape is then used in the correlator element to obtain the final image.

Shuttle Imaging Radar-A (SIR-A)

The Seasat SAR imaged both ocean and land areas and provided the first spaceborne SAR data set. The success of the Seasat SAR mission led to the Shuttle imaging radar series, or SIR series. The first of the Shuttle imaging radars, SIR-A, flew on the second Shuttle flight as part of the first scientific payload to be carried into space by the Shuttle.

The SIR-A was flown on Columbia in November 1981. The flight lasted for 3 days and the radar acquired data during a total time period of $8 \mathrm{~h}$. Even with a brief time period, images were acquired over selected regions in North, Central, and South America, Africa, Asia, and Australia. The total area covered was about $10 \times 10^{6} \mathrm{~km}^{2}$.

The SIR-A sensor is a modified, but similar, version of the Seasat sensor, and it used some of the residual Seasat hardware (Table 1). The main differences in the SIRA sensor were the following: a narrower bandwidth $(6$ vs $19 \mathrm{MHz}$ for Seasat), a larger incidence angle (50 vs $23 \mathrm{deg})$, a narrower swath $(50$ vs $100 \mathrm{~km}$ ), a slightly lower resolution ( 38 vs $25 \mathrm{~m}$ ), but a higher number of looks (6 vs 
4). The SIR-A data were optically recorded on an onboard recorder. This allowed acquisition of data at any desired location around the world within the limitation of the orbital coverage (between latitudes of $40^{\circ} \mathrm{N}$ and $36^{\circ} \mathrm{S}$ ). The "signal film" was retrieved after the Shuttle landing and was processed in an optical correlator to generate the twodimensional imagery.

Seasat and SIR-A were fixed parameter sensors producing images at constant incidence angles of 23 and $50 \mathrm{deg}$, respectively.

The data from these two missions were analyzed using photointerpretive methods. A comparison of the two data sets provided the means of examining variable geometric imaging parameters. The most illustrative comparison is shown in Figs. 22 and 23. Figure 22 is the SIR-A image of the Santa Ynez Mountains in California and Fig. 23 a Seasat mosaic of the same area. The California coastline from Ventura westward through Santa Barbara toward Point Concepcion is dominated by the folded sedimentary layers of the Santa Ynez Mountains. The strike of the layered rocks in the mountains is clearly displayed by the bright linear tones along the scarp slope; the bedding is offset by the Santa Ynez fault in the lower left portion of the image. The dip slopes are indicated by the pattern of flatirons to the north. This pattern is abruptly terminated by the Santa Ynez Fault, which extends the full length of the mountains.

Brightness of the terrain on the SIR-A image varies significantly in response to changes in the local surface roughness. The Little Pine Fault (along the top left of the image), for example, is evidenced by a change from dark

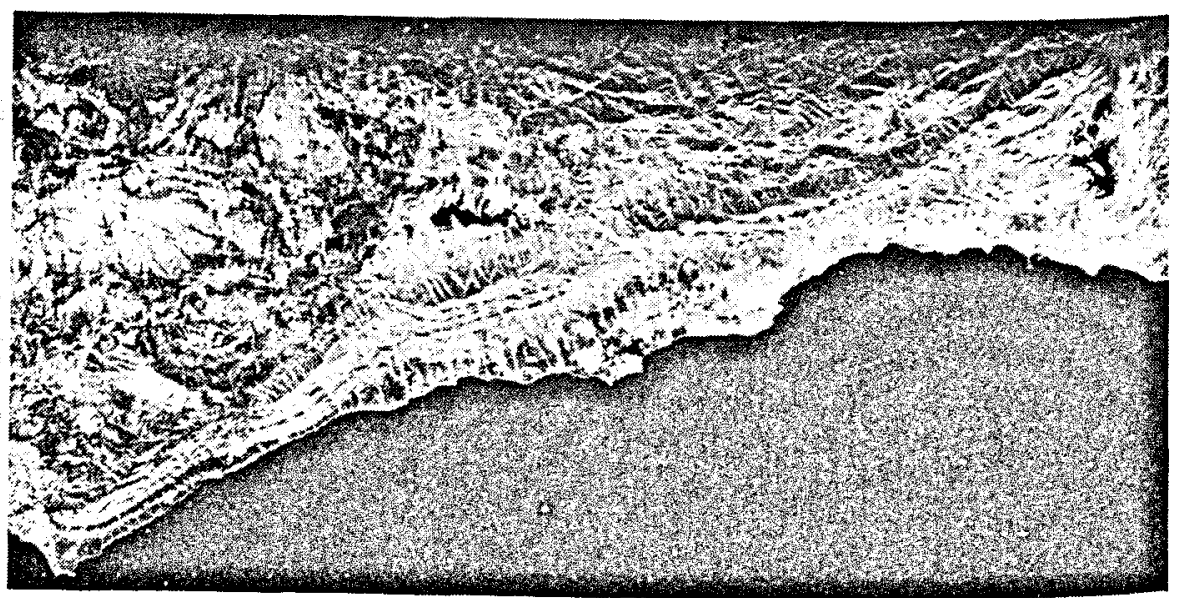

Fig. 22 SIR-A image of the Santa Ynez Range in California acquired with a 50 deg incidence angle. 


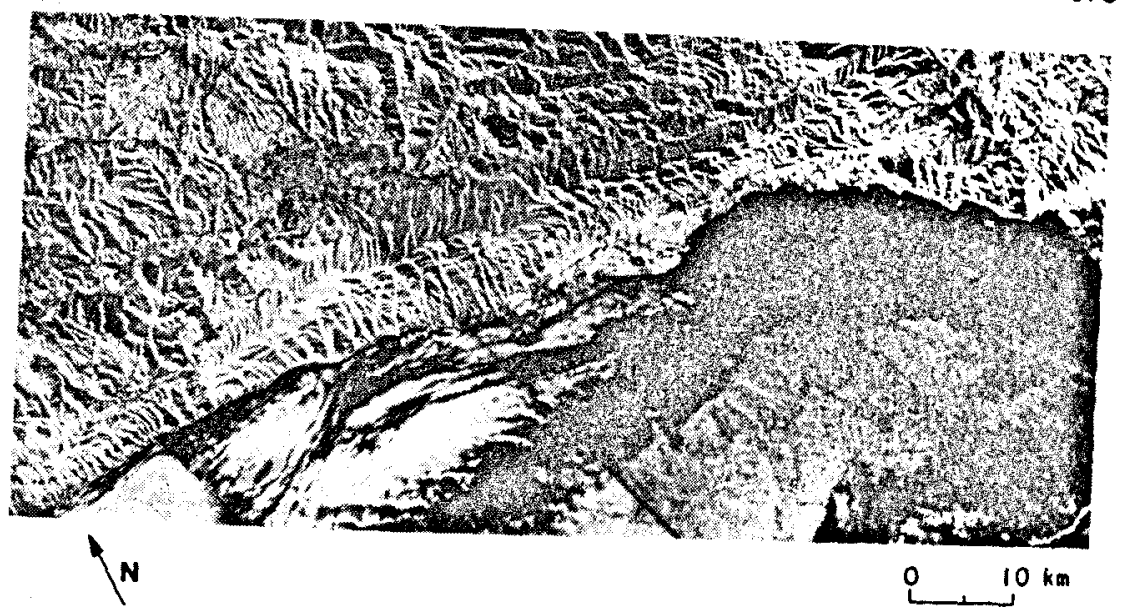
Fig. 23 Seasat image of the Santa Ynez Range in California acquired
with a 23 deg incidence angle.

on the ocean side of the fault to bright on the mainland side. This is because the smoother Plio-Pleistocene sedimentary rocks south of the fault reflect the radar energy away specularly; however, the more rugged Mesozoic ultrabasic intrusive rocks and the Franciscan Formation to the north scatter the radar energy diffusely and produce bright radar returns.

The Seasat image shows significant differences from the SIR-A image due to the different incidence angle. Bedding along the Santa Ynez Range in the Seasat image is obscured by the dominant returns from the steep slopes of the drainages; however, on the SIR-A image the bedding is quite pronounced. The drainage channels normal to coastline are easily traceable on the SIR-A image, but on the Seasat image are obscured because of layover. On the other hand, many of the drainage patterns shown on the Seasat image are not seen on the SIR-A image. The above differences are due to differences in local incidence angle of the Seasat and SIR-A images.

The effect of variable incidence angle is further emphasized in the radar returns from the ocean surface. Small changes in the ocean surface topography are easily discernible on the Seasat image because small changes in the local slope result in large changes in the backscatter at the steep incidence angle of $23 \mathrm{deg}$.

Shuttle Imaging Radar-B (SIR-B)

With the launch of SIR-B, NASA took the next step in an evolutionary radar program toward a final multifrequency, 
multincidence angle, multipolarization imaging radar system.

The SIR-B instrument is an upgraded SIR-A with the additional capability of tilting the antenna mechanically to acquire data at incidence angles of 15-60 deg. Like Seasat and SIR-A, SIR-B will be an L-band, HH polarized radar (Table 1). The variable incidence angle capability will allow several new potential experiments. A specific area may be imaged with a variety of incidence angles on successive days. Images acquired at variable incidence angles can be registered and used to produce curves of backscatter as a function of the incidence angle for various terrain types. These curves can ultimately be used to characterize the terrain. Stereo imaging may also be done in the multiple incidence angle mode. In addition, large areas may be imaged and mosaicked together with only slight variations in the incidence angle with each swath.

In addition to the variable look angle capability, SIR$B$ has an increased bandwidth, an additional antenna panel, and a digital data processing system. The increased bandwidth will improve the range resolution by a factor of two. At a $47 \mathrm{deg}$ look angle, the resolution will improve from $38 \mathrm{~m}$ on SIR-A to $19 \mathrm{~m}$ on SIR-B. The additional antenna panel will increase the length of the antenna from $9.4 \mathrm{~m}$, making the overall dimensions of the SIR-B radar antenna $10.7 \times 2.1 \mathrm{~m}$. The increased antenna area will improve the SNR slightly, which is important at the larger look angles. The digital data capability will allow data to be sent through a digital data handling system (DDHS) onboard the Shuttle to the ground receiving station at White Sands, NM, via the Tracking and Data Relay Satellite (TDRS). The data rate for SIR-B is 46 megabit/s, which can be handled in real time by the $\mathrm{Ku}$-band 50 megabit/s TDRS link. The digital capability will allow for the first time quantitative and analytical studies of the effects of the varying illumination geometry on the radar image. In addition to acquiring data directly through TDRS, digital data may also be recorded on a digital tape recorder mounted on the a ft flight deck of the shuttle when the TDRS is not in view of the Shuttle and then later transmitted through TDRS or stored on tape onboard the shuttle. A more detailed description of the DDHS is given below.

\section{The Digital Data Handling Subsystem}

The digital data handling system (DDHS) is a new piece of hardware that has been specially constructed for the SIR$B$ instrument. It adds a digital recording capability to 
the radar. With the DDHS, the radar's video signal, containing the backscattered echo, is digitized to a resolution of up to 6 bits and recorded on the shuttle or beamed to a ground station on Earth for recording.

The DDHS is constructed of five main assemblies, as shown in Fig. 24. The ADC (analog-to-digital converter) assembly performs the digitization of the video signal to a fixed 6 bit quantization level. The conversion rate is set by the frequency of the input composite clock-and-synchronous signal. For SIR-B the conversion rate is $30.353 \mathrm{MHz}$. The output digitized words are fed to six holding registers in the $A D C$ that are then transfered to the buffer assembly at a rate of $30.353 / 6=5.069 \mathrm{MHz}$ during the data latch event. The sync portion of the composite clock-and-sync signal is recovered in the $A D C$ and used to toggle the buffer assembly between its ping-pong memories. The sync signal

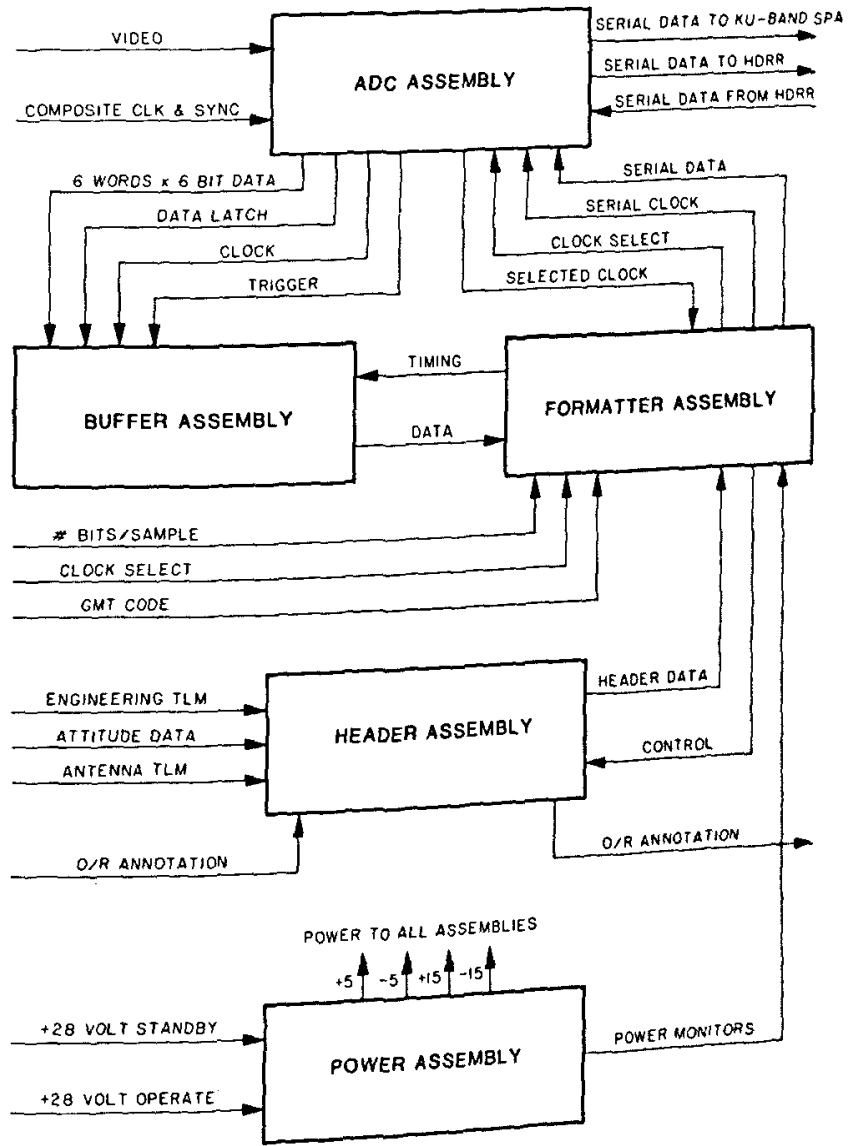

Fig. 24 Functional block diagram of the SIR-B DOHS. 
is generated in the SIR-B electronics and begins the digitization window (i.e., the recording window) of the DDHS.

The buffer assembly stores the sampled data for one range line (i.e., one recording window) in one memory while outputting the previous range line's data from another memory. This technique is commonly called "ping-pong" buffering. Each of the two memories in the buffer assembly can store 12,000 six-bit words. Data are continuously read into the memory until it becomes full. Data are read out of the buffer assembly to the formatter assembly as 3,4 , 5 , or 6 bit words, depending on the bits/sample control lines from the radar. The number of bits per sample is a variable that may be selected by an investigator. Inasmuch as the total data rate is 1 imited to 45 or 30 megabit/s, it is possible to select fewer bits per sample in order to increase the swath width of an image or, alternatively, to select more bits per sample, which results in a more dynamic range but a reduced swath. The most significant bits are transfered and the least significant bits are ignored.

The formatter assembly takes the parallel-fed data from the buffer, mixes it with housekeeping and header data, and creates a serial bit stream for recording. The serial bit stream is fed to the ADC assembly, which has high-speed, high-power line drivers to drive the long coaxial cables to the Ku-band signal processor assembly and the high data rate recorder (HDRR). The formatter can create the serial bit stream at two rates: 45 megabit/s for the Ku-band link or 30 megabit/s for the HDRR. Only one rate can be selected at a time using the clock select command line from the SIR-B electronics. When the 30 megabit/s rate is chosen, data can be output to the HDRR or read from the HDRR and output to the Ku-band link.

The header assembly generates a pseudo noise code sequence to define the beginning of each range line of data. The pseudo noise code is specially selected and is the same for each range line. It can be easily picked out of the radar data in the ground processing. Following the pseudo noise code is housekeeping and engineering data, including the spacecraft attitude and radar antenna angle. The header assembly also outputs this information to the optical recorder as an annotation to be placed on the film alongside the video data.

The power assembly converts the unregulated spacecraft d.c. power to regulated d.c. power for the DDHS. Both the standby and operational sets of power supplies are used. When digital recording is not required, the DDHS is powerd down to the standby mode to conserve power. In the standby 
mode, the DDHS will still provide annotation for the optical recorder.

Each of the five assemblies is constructed as a separate module. All five modules are stacked to form the complete assembly. The overall size of the assembly is $18.5 \mathrm{in}$. wide by $10.0 \mathrm{in}$. high by $10.5 \mathrm{in}$. deep. The power supply is the bottom module, followed by the ADC, buffer, formatter, and header assemblies from the power supply up. The buffer, header, and formatter assemblies use wire-wrap techniques for interconnection between the integrated circuits. The $A D C$ assembly, because of its high operating speed, uses multilayer printed-circuit boards with controlled-impedance transmission lines for interconnections between integrated circuits. The DDHS uses $100 \mathrm{~K}$ ECL, $10 \mathrm{KECL}$, STTL, TTL, LSTTL, NMOS, and CMOS integrated circuits in its design.

The DDHS is mounted on a heat exchanger on the pallet alongside the SIR-B optical recorder. The hottest modules are placed on the bottom of the DDHS for good thermal conduction to the heat exchanger.

The SIR-B experiment was launched on the Space Shuttle Challenger into a nominally circular orbit at an inclination of $57 \mathrm{deg}$ and an average altitude of $360 \mathrm{~km}$ for the first 20 orbits, $272 \mathrm{~km}$ for the next 13 orbits, and $225 \mathrm{~km}$ for the duration of the mission.

\section{SAR Optical Processors}

The SAR sensor provides a record of the received echoes forming the signal data. The signal data is processed in either an optical or digital processor to generate the synthetic aperture providing the final high-resolution image Optical techniques for processing SAR data were developed primarily in the 1960 s for airborne SAR systems. ${ }^{33,34}$ Modifications were then developed to account for additional effects encountered in spaceborne systems.

The phase history generated by a point target is similar to a Fresnel zone plate. This fact makes SAR data natural candidates for optical processing. Since the phase function is quadratic in both dimensions, it diffracts a coherent plane wave, illuminating it into a converging beam that will focus at a point. Unfortunately, the converging wave will come to a focus at different distances from the zone plate for the range and azimuth directions. These distances are referred to as the range and azimuth focal lengths, respectively. Not only is the azimuth focal length different from the range focal length, but it varies linearly with the range dimension. This linear variation 
can be compensated for by using a conical lens. Manufacturing such lenses is difficult, however, and a cylindrical lens rotated about the horizontal axis leads to the same compensation.

The configuration of the Seasat and SIR-A processors with the tilted-lens mode of operation is shown in Fig. 25. A confocal, spherical lens pair, called the range telescope, images the range and azimuth focal planes. A three-lens cylindrical telescope demagnifies the azimuth dimension. An auxiliary lens pair composed of a tilted azimuth cylinder and a vertical azimuth cylinder are used at the output of the azimuth telescope to bring the azimuth image into coincident focus with the range image. Frequency filtering and range migration correction are done at the back focal plane of the first spherical lens by a combination of cylindrical lenses. A relay lens magnifies an intermediate image onto the output film drive. The spatial filter is composed of a microscope objective lens and a pinhole. The pinhole is located at the back focal point of the objective, blocking out spatial noise in the laser beam. Thus, a "clean" diverging spherical wave emerges from the filter. For the detailed description, the reader is refered to Ref. 7 .

\section{SAR Digital Processors}

The basic concept of SAR processing is to correlate the signal time-phase history with a reference waveform and to conduct the corrections due to Earth rotation, range

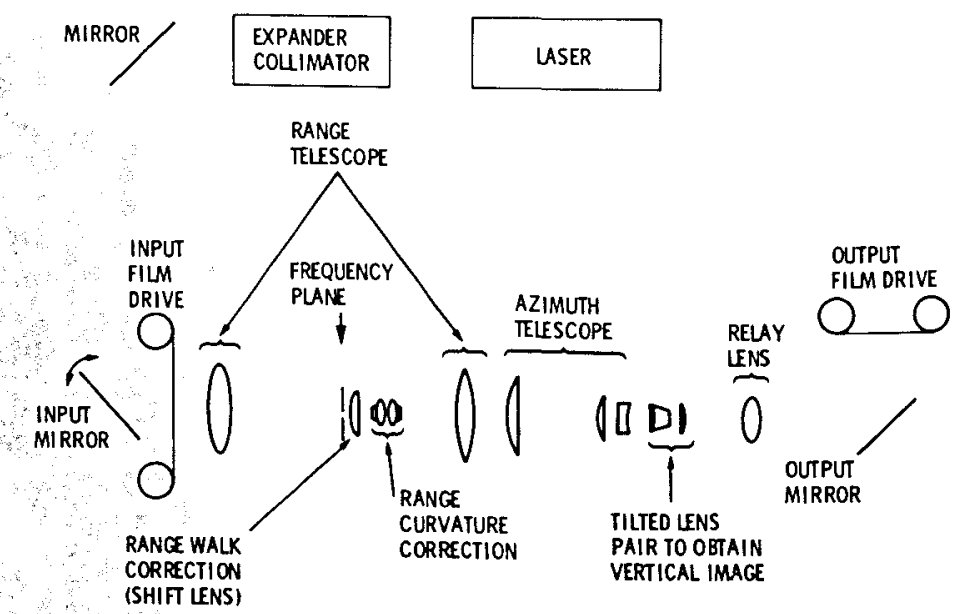

Fig. 25 Elements of Seasat and SIR-A optical processor. 
curvature, and range walk. The development of digital SAR processing techniques has two aspects: 1) to de fine the SAR response of a point target as well as a continuous field of reflecting targets, and 2) to develop algorithms that will allow processing in an efficient and fast thruput fashion. This is important because of the very large number of computations usually associated with the processing of spaceborne radar data. A number of algorithms have been implemented based on time domain convolution or frequency domain correlation (see Refs. 35-38). For an overview of these different techniques the reader is refered to Ref. 7 .

\section{Future Development and Conclusions}

The Seasat SAR, SIR-A and SIR-B operated at a single frequency band (L) and single polarization (HH). In order to fully utilize the capability of active microwave sensing of the surface, multiparameter imaging radar systems will be required. Such systems are planned for flight in the late 1980s.

When a radar signal interacts with the surface, the returned echo contains both a polarized (same as the incident polarization) and a depolarized component. In order to fully describe the wave/surface interaction, the full polarization matrix is required. A multipolarization radar sensor should be able to transmit both horizontal (H) and vertical (V) polarization quasisimultaneously (i.e., in approximately millisecond time scale) and coherently receive both $H$ and $V$ polarization simultaneously. The polarization information will help in separating returns from the surface interface vs the return from volume scattering in the surface cover (such as vegetation) or subsurface layer (such as sand or alluvium). Plate 16 (see color section of this volume) gives an example of such multipolarization data acquired with an airborne imaging radar. The data were acquired March 1, 1984 using the NASA/JPL airborne L-band SAR system. The swamp area produces bright returns at each polarization due to multiple radar reflections from tree and water surfaces. The dark linear strips are mostly clearcuts in the pine forest. Young pine stands produce strong HH returns that appear red on the image; older, more dense pine canopy provides strong $V H$ returns that appear blue.

The interaction of the radar signal with the surface and near subsurface is also strongly dependent upon the signal frequency. The penetration depth is linearly proportional to the signal wavelength. Thus a multifrequency imaging radar will be able to probe to different depths 
below the surface interface. In addition, the return is dependent on the physical scale of the scatterer relative to the wavelength. Therefore, a measure of the surface roughness or scatter size distribution spectrum can be obtained, thus providing one mechanism to separate surface units.

The next step in the U.S. spaceborne imaging radar program is the development of a multifrequency (at least Land (-band) multipolarization sensor, called SIR-C, to fly on the Shuttle in the late 1980s. An X-band channel might be added by concurrently flying the German microwave remote sensing experiment (MRSE). This would be followed by a multiparameter electronically scanning imaging radar system to be developed for the Shuttle and the space station in the early 1990s. In addition, early development is in progress for a Shuttle scanning radar altimeter that would allow the acquisition of global digital topographic data of the land surface with a spatial resolution of about 100$200 \mathrm{~m}$ and a height resolution of a few meters.

For long-term global observation, two free-flying imaging radar systems are being planned for the late 1980s, one on the Japanese Earth Resource Satellite and the other on the European Earth Resource Satellite. The Japanese system will emphasize global mapping of the land surface for geologic and land use applications, while the European system will emphasize oceanographic applications. Both systems will have a fixed configuration and a fixed set of parameters. A Canadian system with a very wide accessible swath capability is planned in the 1990 s for continuous monitoring of the polar ice cover.

\section{Acknowledgments}

A number of sections in this chapter are based on papers and reports written by a number of our colleagues at the Jet Propulsion Laboratory. We would like to particularly acknowledge the work by T. Bicknell, E. Caro, R. Jordan, and $C$. Wu from JPL who have made major contributions in the development of Seasat, SIR-A, and SIR-B. The authors would like also to acknowledge the support of Ms. M. Fullmer in typing the manuscript and Ms. S. Salas in preparing the artwork.

The research described in this paper was performed at the Jet Propulsion Laboratory, California Institute of Technology, under contract with the National Aeronautics and Space Administration. 


\section{References}

1Born, G.H., Dunne, J.A., and Lame, D.B., "Seasat Mission Overview," Science, Vol. 204, 1979, pp. 1405-1406.

2Elachi, C. et al., "Shuttle Imaging Radar Experiment," Science, Vol. 218, 1982, pp. 996-1003.

3Elachi, C., "Spaceborne Imaging Radar: Geologic and Oceanographic Applications," Science, Vol. 209, 1980, pp. 1073-1082.

4 Vesecky, J.F. and Stewart, R.H., "The Observation of the Ocean Surface Phenomena Using Imagery from the Seasat SAR: An Assessment," Journal of Geophysical Research, Vol. 87, 1982, pp. 33973430 .

5Ulaby, F., Razani, M., and Dobson, M., "Effects of Vegetation Cover on the Microwave Radiometric Sensitivity to Soll Moisture," IEEE Transactions on Remote Sensing, Vol. GE-21, 1983, pp. 51-61.

$6_{F u}$, L. and Holt, B., "Internal Waves in the Gulf of Callfornia; Observation from a Spaceborne Radar," Journal of Geophysical Research, Vo1. 89, 1984, pp. 2053-2060.

7Elachi, C., Bicknell, T., Jordan, R.L., and Wu, C., "Spaceborne Synthetic Aperture Imaging Radar: Applications, Techniques and Technology," Proceedings of IEEE, Vol. 70, 1982, pp. 1174-1209.

8 McCauley, J. et a1., "Subsurface Valleys and Geoarcheology of the Eastern Sahara Revealed by Shuttle Radar," Science, Vol. 218, 1982, pp. 1004-1020.

${ }^{9}$ Cimino, J.B. and Elachi, C., "The Shuttle Imaging Radar-A Experiment," JPL Pub. 82-77, 1982.

10 Brown, W.M. and Porcello, L.J., IRE Transactions on Military Electronics, MIL-6, 1969, p. 111.

11Cutrona, L.J., "Synthetic Aperture Radar," Radar Handbook, edited by M.I. Skolnik, McGraw-Hill Book Co., New York, $19 \overline{70 .}$

12 Harger, R.0., Synthet ic Aperture Radar Systems, Theory and Design. Academic Press, New York, 1970.

13Jensen, H., Graham, L.C., Porcello, L.J., and Leith, E.N., Scientific American, Vol. 237, 0ct. 1977, p. 84.

14 Tomiyasu, K. "Tutorial Review of Synthetic Aperture Radar with Application to Imaging of the Ocean Surface," Proceedings of IEEE, Vol. 66,1978, p. 563.

15Bennett, J.R. and McConnell, P.R., "Considerations in the Design of 0ptimal Multilook Processors for Imaging Quality," SAR Image Quality Workshop, Paper ESA SP-172, Frascati, Italy, December 1980. 
16Ford, J.P., "Seasat Orbital Radar Imaging for Geologic Mapping: Tennesseee-Kentucky-Virginia," American Association of Petroleum Geologists Bulletin, Vol. 64, 1980, pp. 2064-2094.

17Sabins, F.F., Blom, R., and Elachi, C., "Seasat Radar Image of the San Andreas Fault, Cali fornia," American Association of Petroleum Geologists Bulletin, Vol. 64, 1980, pp. 614.

18B $\mathrm{B}$ om R. and Elachi, C., "Spaceborne and Airborne Imaging Radar Observation of Sand Dunes," Journal of Geophysical Research, Vol. 86, 1981, pp. 3061-3070.

${ }^{19}$ Ford, J., Cimino, J.B., and Elachi, C., "Space Shuttle Columbia Views the World with Imaging Radar," Jet Propulsion Laboratory, Pasadena, CA, JPL Pub. 82-95, 1983.

${ }^{20}$ Sabins, F.F., "Geologic Interpretation of Space Shuttle Radar Images of Indonesia," American Association of Petroleum Geologists Bulletin, Vol. 67, 1983, pp. 2076-2099.

21Elachi, C., Roth, L., and Schaber, G., "Spaceborne Radar Subsurface Imaging in Hyperarid Regions," IEEE Transactions of Geoscience and Remote Sensing, Vol. GE-22, $1984, \mathrm{pp} . \frac{\mathrm{Transaction}}{383-388 .}$

22Blom, R., Crippen, $R_{.}$, and Elachi, C., "Detection of Subsurface Features in Seasat Radar Images of Means Valley, Mojave Desert, California," Geology, Vol. 12, 1984, pp. 346-349.

$23_{\text {Beal, R.C., Deleonibus, P.S., and Katz, I., Spaceborne Synthetic }}$ Aperture Radar for Oceanography, Johns Hopkins University Press, Baltimore, MD, 1981.

24Elachi, C. and Brown, W.E., "Models of Radar Imaging of the Ocean Surface Waves," IEEE Transactions on Antennas and Propagation, Vol. AP-25, Jan. 1977, pp. 84-95; aTso IEEE Journal of Oceanic Engineering, Vol. OE-2, Jan. 1977, pp. 84-95.

25Alpers, W.R. and Rufenach, C.L., "The Effect of Orbital Motion on Synthetic Aperture Imagery of Ocean Waves," IEEE Transactions on Antennas and Propagation, Vol. AP-27, 1979, pp. $635-690$.

26 Alpers, W.R., Ross, D.B., and Rufenach, C.L., "On the Detectability of Ocean Surface Waves by Real and Synthet ic Aperture Radars," Journal of Geophysical Research, Vol. 86, 1981, pp. 6481-6498.

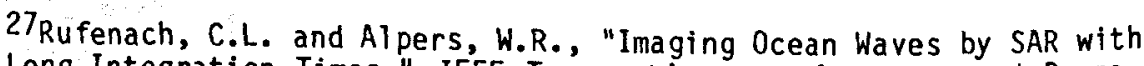
Long Integration Times," IEEE Transactions on Antennas and Propagation, Vol. AP-29, 1981, $\mathrm{pp} .422-428$.

28 Garrett, H.E. and Hughes, B.A., "On the Interaction of Surface and Internal Waves," Journal of Fiuid Mechanics, 1972, pp. 179-191.

29Elachi, C. and Apel, J., "Internal Wave Observations Made with an Airborne Synthetic Aperture Imaging Radar," Geophysical Research Letters, Vol. 3, 1976, pp. 647-750. 


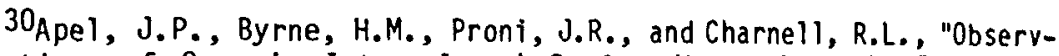
ations of Oceanic Internal and Surface Waves from the Earth Resources Technology Satellite," Journal of Geophysical Research, Vol. 80, 1975, pp. 865-881.

31Jordan, R.L., "The Seasat-A Synthetic Aperture Radar System," IEEE Journal of Oceanic Engineering, Vol. OE-5, 1980, pp. 154-163.

${ }^{32}$ Elachi, C. et al., "Shuttle Imaging Radar (SIR-A) Experiment; Preliminary Results," Science, in press.

33Goodman, J.W., Introduction to Fourrier Optics, MeGraw-Hill Book Co., New York, 1968.

${ }^{34}$ Kozma, A., Leith, E.M., and Massey, N.G., "Tilted Plane Optical Processor," Applied Optics, Vol. 11, 1972, pp. 1766-1777.

35Cumming, I.G. and Bennett, J.R., "Digital Processing of Seasat SAR Data," Proceedings of IEEE International Conference on Acoustic, Speech, Signal Processing, 1979, pp. 710-717.

36Vant, M.R., Herring, R.W., and Shaw, E., "Digital Processing Techniques for Satellite Borne Synthetic Aperture Radar," Canadian Journal of Remote Sensing, Vol. 5, No. 1, 1979.

${ }^{37}$ Truong, T.K., Reed, I.S., Lipes, R.G., and Wu, $C_{\text {., }}$ "On the Application of a Fast Polinominal Transform and the Chinese Remainder Theorem to Compute a Two-Dimensional Convolution," $\frac{\text { IEEE }}{\text { P. }}$ Transactions on Acoustic, Speech, Signal Processing, Vol. ASsP-29, No. 1, Feb. 1981, pp. 91-97.

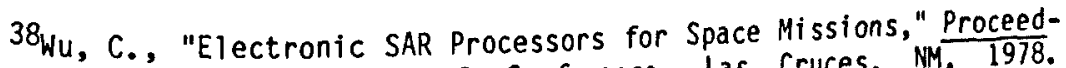
ings of the SAR Technical Conference, Las Cruces, NM, 1978. 39 Ulaby, F., Moore, R., and Fung, A., "Microwave Remote Sensing," Addison-Wesiey Publishing Company, 1982. 